\section{Institucionalização das ciências, sistema de gênero e produção científica no Brasil (1939-1969)}

\section{Institutionalization of the sciences, gender system, and scientific production in Brazil (1939-1969)}

Luiz Otávio Ferreira

Pesquisador da Casa de Oswaldo Cruz/ Fundação Oswaldo Cruz; Universidade do Estado do Rio de Janeiro Av. Brasil, 4366 sala 406 21040-900 Rio de Janeiro - RJ - Brasil lotavio@coc.fiocruz.br

Nara Azevedo

Diretora e pesquisadora da Casa de Oswaldo Cruz/ Fundação Oswaldo Cruz Av. Brasil, 4365 Prédio do Relógio 21040-900 Rio de Janeiro - RJ - Brasil nazevedo@fiocruz.br

\section{Moema Guedes}

Doutoranda em demografia no Instituto de Filosofia de Ciências Humanas/Universidade de Campinas Rua Almirante Alexandrino,1876/ apto. 302 20241-261 Rio de Janeiro - RJ - Brasil moguedes@yahoo.com.br

\section{Bianca Cortes}

Pesquisadora da Casa de Oswaldo Cruz / Fundação Oswaldo Cruz Av. Brasil, $43666^{\circ}$ andar 21040-900 Rio de Janeiro - RJ - Brasil bcortes@coc.fiocruz.br

Recebido para publicação em novembro de 2007. Aprovado para publicação em março de 2008.
FERREIRA, Luiz Otávio et al.

Institucionalização das ciências, sistema de gênero e produção científica no Brasil (1939-1969). História, Ciências, Saúde Manguinhos, Rio de Janeiro, v.15, supl., p.43-71, jun. 2008.

As experiências de educação feminina em nível superior, proporcionadas pelas políticas educacionais implantadas a partir da década de 1930, promoveram a inserção profissional de mulheres no mundo acadêmico e científico. Largamente negligenciada na historiografia brasileira das ciências, a análise desse fenômeno lança uma nova perspectiva sobre o sentido da institucionalização e profissionalização da atividade científica, processo no qual as mulheres atuaram efetivamente. Procuramos identificar sua presença ali, por meio da análise da produção científica presente em quatro revistas, no período entre 1939 e 1969 , evidenciando-se diferenças de sexo quanto ao padrão de publicação.

Palavras-chave: produção científica feminina; gênero e ciências; educação feminina; universidades no Brasil; faculdades de filosofia, ciências e letras.

FERREIRA, Luiz Otávio et al. Institutionalization of the sciences, gender system, and scientific production in Brazil (1939-1969). História, Ciências, Saúde - Manguinhos, Rio de Janeiro, v.15, Suppl., p.43-71, June 2008.

Thanks to policies put in place in the 1930s, women's experiences in higher education increased their professional participation in the academic and scientific worlds. Largely neglected in Brazilian historiography of the sciences, analysis of this phenomenon introduces a new perspective on the meaning of institutionalization and professionalization of scientific activities, a process in which women have played an authentic role. We explore their presence by analyzing the scientific production published in four journals between 1939 and 1969. Gender differences are detected according to the standard of the publication.

Keywords: women's scientific production; gender and sciences; women's education; universities in Brazil; schools of philosophy, science, and arts. 
Luiz Otávio Ferreira et al.

$\mathrm{E}$ $m$ trabalho anterior, procuramos verificar em que medida a intensificação da escolarização feminina na década de 1930 pode ser interpretada como um fenômeno interdependente com a mudança no sistema de gênero naquele período, a qual, por sua vez, se inscrevia no processo de modernização em curso. Ali chamamos a atenção para o fato de que a alteração de hábitos e costumes familiares, associada à urbanização e à emergência de um novo estilo de vida burguesa, promoveu resultados amplos e inesperados. As experiências de escolarização em diversos níveis, proporcionadas pelas políticas sociais e, em particular, pelas políticas educacionais - implantadas a partir dos anos 20 e institucionalizadas durante a chamada era Vargas -, determinaram novas oportunidades profissionais para as mulheres, especialmente as que pertenciam às camadas urbanas médias e altas, que, decididamente, se direcionaram para o mundo do trabalho não doméstico, procurando ocupação nos setores de produção de bens e serviços (Azevedo, Ferreira, jul.-dez. 2006).

Se a educação, entre outros aspectos mais amplos, pode ser vista simultaneamente como causa e efeito da mudança operada nos papéis femininos, ela também imprimiu uma decisiva direção ao ingresso de mulheres no mundo acadêmico e científico. Neste artigo, procuramos avançar a investigação a respeito desse processo, indagando como a crescente escolarização em nível superior, que ocorreu a partir da década de 1940, encaminhou contingentes expressivos de mulheres às instituições científicas, e como esse recrutamento repercutiu na institucionalização da ciência em um momento caracterizado pelo aprofundamento da profissionalização da atividade de pesquisa, decorrente do movimento simultâneo da política estatal - inaugurada com o CNPq em 1951 - e da mobilização da coletividade científica (Schwartzman, 2001; Andrade, 1999; Botelho, 1990; Fernandes, 2000, Ribeiro, 1998).

Para tanto, analisamos quatro revistas científicas - Anais da Academia Brasileira de Ciência, Revista Brasileira de Biologia, Memórias do Instituto Oswaldo Cruz e Revista Brasileira de Malariologia e Doenças Tropicais - no período que se estende entre 1939 e 1969, em que se detecta uma significativa presença de artigos femininos, bem como diferenças quanto ao padrão de publicação entre mulheres e homens.

O principal argumento desenvolvido é o de que tal resultado pode ser interpretado como um efeito do 'deslizamento' das relações de gênero, prevalecentes na sociedade brasileira, para a dinâmica das instituições científicas. Se, por um lado, tal efeito contribuiu para uma distribuição desigual de poder nessas instituições - expressa no controle e no acesso diferenciados a recursos materiais e simbólicos -, confirmando, portanto, a posição social subordinada das mulheres na sociedade brasileira, por outro lado impulsionou sua incorporação a um lugar do qual estavam excluídas ou em que era rara a sua presença, refletindo as transformações do sistema de gênero, que, não sem ambigüidade, redefiniu os papéis sociais femininos.

Explorar os elos entre relações de gênero e história da ciência constitui o principal propósito deste trabalho. Partindo do pressuposto segundo o qual a atividade científica pode ser tratada como uma profissão similar às demais - noção decorrente da dessacralização da ciência como atividade social, operada pela sociologia do conhecimento científico pelo menos desde o Programa Forte, e sobretudo pelos pioneiros estudos de laboratório da 
década de 1970 -, é plausível pensar que as diferenças entre as carreiras científicas de homens e mulheres - registradas pelos estudos que investigam como as relações de gênero influenciam a posição social das mulheres nas ciências - sejam similares àquelas que ocorrem nas demais profissões, e que tais diferenças resultem da interdependência entre as hierarquias sociais de gênero e o sistema de estratificação da ciência.

A aproximação preliminar dessa complexa questão, ensejada pela investigação a respeito da produção científica feminina, pretende contribuir para alargar a perspectiva do debate historiográfico sobre as relações entre sistema de gênero e institucionalização das ciências no Brasil. ${ }^{1}$ Além do reconhecimento da presença feminina na institucionalização das ciências no Brasil, também são consideradas as implicações de gênero inscritas nesse processo. A escassez de estudos históricos com tal preocupação contribui para a percepção social de que as mulheres estão ausentes das ciências, ou que, quando ali são identificadas, representam a exceção. Essa invisibilidade constitui mais um problema da historiografia do que da história, representando um obstáculo ao avanço de uma perspectiva historiográfica inovadora, capaz de traçar um quadro no qual figurem não apenas um punhado de mulheres notáveis, mas também as incontáveis anônimas que, no Brasil, a partir da década de 1940, adentraram contínua e decisivamente os laboratórios de pesquisa. Trata-se, assim, de deslocar o olhar de casos particulares para um fenômeno coletivo, capaz de ampliar a compreensão sobre as mudanças institucionais verificadas após a Segunda Guerra Mundial, a partir de uma visão menos homogeneizadora e mais inclinada a permitir a emergência de conflitos e diferenças que marcam as relações e os processos sociais. Por que a ciência constituiria uma exceção?

Em torno desses argumentos o texto se desenvolve, abordando na primeira seção as diferenças de sexo quanto à publicação, reconhecidas pelos estudiosos como um problema a ser decifrado. Apresentamos alguns aspectos dessa questão ressaltados pela literatura e que contribuíram para a nossa análise. A segunda seção trata da educação feminina em nível superior, salientando o papel das faculdades de filosofia, criadas nas primeiras universidades que surgiram na capital federal e em São Paulo na década de 1930. Destacamos as implicações dessas instituições para a incorporação de mulheres à atividade científica e, por conseguinte, para o processo de institucionalização em curso naquele período. No tópico seguinte, apresentamos alguns traços institucionais das revistas selecionadas, aos quais correlacionamos o padrão de publicação de mulheres e homens, que procuramos caracterizar na última seção do texto.

\section{Por que as mulheres publicam menos?}

Nas últimas três décadas, estudos com diferentes perspectivas analíticas registram a presença de mulheres na ciência, contestando de modo veemente a invisibilidade a que foram condenadas pela historiografia até a década de 1970 (Rossiter, 1993, p.331; 1984, p.xi; Fox, 1995, p.205). Uma importante vertente de investigação é a que trata da produtividade científica. Apesar da distorção na distribuição de publicações científicas, relacionada ao padrão constatado por Price (1969), segundo o qual a maioria dos trabalhos científicos é publicada por poucos, enquanto a maioria publica pouco ou nada, as 
publicações representam um processo social fundamental no intercâmbio e na validação do conhecimento científico entre os pares, correlacionando-se diretamente com o impacto da pesquisa e as recompensas acadêmicas que lhes correspondem. ${ }^{2}$ Nesse sentido, a diferença de sexo em termos de publicações constitui uma questão relevante e ainda não esclarecida. Indaga-se: por que as mulheres publicam menos?

A menor produtividade das mulheres é ressaltada em inúmeros estudos referentes aos mais variados campos científicos, observados durante longos períodos e em diferentes países. Verifica-se que ao longo da carreira, na média, mulheres publicam menos da metade do que os pares homens, o que sugere que o sexo constitui uma importante fonte de variação e se correlaciona à publicação (Zuckerman, Cole, Bruer, 1991, p.13; Long, 1992, 1990; Zuckerman, 1991, p.43; Fox, Faver, 1985, p.537; Fox, 1995, p.216). Observa-se também que as diferenças entre os sexos tendem a acumular desvantagens para as mulheres e vantagens para os homens (Rossiter, 1993, p.327) ${ }^{3}$ e são determinantes para o desenrolar da carreira aquelas (vantagens e desvantagens) que se manifestam no início, ainda durante a formação em nível de doutoramento. ${ }^{4}$

Se a constatação dessa disparidade é amplamente reconhecida, não há consenso a respeito dos fatores que a determinam, nem existem indicadores universalmente aceitos para mensurar de forma adequada os diferentes níveis de produtividade entre os sexos. Em geral, o número de publicações e o de citações são os mais utilizados, considerando-se também outros indicadores, tais como o número de co-autores, a posição do autor no artigo, a amplitude e a natureza das colaborações (mentor, marido e colegas) e a freqüência das publicações no tempo. Embora as investigações, baseadas em metodologias quantitativas, procurem flagrar as diferenças de gênero em descrições pormenorizadas dessas variáveis, dois fatores em particular atraem o interesse dos estudiosos: casamento e maternidade. Freqüentemente esses fatores são mais relacionados às mulheres do que aos homens. Contudo, não há consenso quanto às suas implicações sobre as carreiras das mulheres, nem quanto ao modo como devem ser abordados. De fato, as opiniões se dividem, e diferentes e contraditórios resultados são apresentados: o casamento pode gerar efeitos positivos sobre a produtividade de ambos os sexos ou somente sobre os homens. Porém, observa-se que as mulheres são mais influenciadas pela presença de filhos - em um gradiente de efeitos de menor a maior intensidade conforme a idade - do que pelo casamento (Long, 1990, p.1299). Evidências contrárias também são apontadas, segundo as quais nem casamento nem filhos teriam influência sobre a produtividade. A noção de que bons cientistas são homens casados ou mulheres sem marido e filhos não passaria, portanto, de uma mitologia da ciência. Uma série de investigações sobre diferentes disciplinas indica que mulheres casadas publicam mais do que as solteiras e que a presença de filhos não apresenta nenhum efeito significativo ou positivo, sendo apenas ligeiramente negativa (Fox, 2005, p.132). Argumenta-se, além disso, que a ênfase na maternidade configura uma explicação intrínseca e determinista sobre o status da mulher na ciência, cuja implicação é a de que os papéis de gênero e status são governados por fatores que dificilmente podem ser alterados social e organizacionalmente. Esse aspecto é ressaltado por Fox (p.132), que considera as relações entre gênero, produtividade científica e família mais complexas do que simplesmente 'ser ou não casada', e 'ter ou não filhos'. Para as mulheres, a relação entre casamento e produtividade varia de acordo com o tipo de casamento (se primeiro ou 
subseqüente) e com a ocupação do marido. Mulheres em casamentos subseqüentes têm maior produtividade do que aquelas em primeiras núpcias, e isso se relaciona com o padrão habitual de casamento com outro cientista, que redunda em efeitos positivos sobre a produtividade das mulheres. Quando se observa a composição familiar, entretanto, homens e mulheres diferem de modo notável. Na análise que Fox empreendeu sobre os dados de um survey nacional, conduzido nos Estados Unidos entre 1993 e 1994, a maioria das mulheres (52\%) não tem nenhum filho, contrastando com $21 \%$ dos homens. Em compensação, é notável a alta produtividade de mulheres com filhos na pré-escola, em comparação com mulheres sem filhos ou com filhos em níveis escolares mais avançados (p.140).

Uma posição polêmica a respeito dessa questão é defendida por Jonathan Cole (1987). Embora constate o baixo número de publicações de mulheres comparativamente ao de homens, Cole considera frágil a associação entre maternidade, casamento e produtividade científica, e defende a hipótese segundo a qual, na ciência, sexo e raça são "características funcionalmente irrelevantes", que atuam na falta de critérios "funcionalmente relevantes de julgamento da performance individual" (p.75). Além disso, o status de sexo importa mais em uma situação social caracterizada por baixa ou nenhuma publicação, do que naquela em que os cientistas são produtivos. Ou seja, na ausência de publicações para certificar o conhecimento, cientistas que se encontram na posição de julgar os demais podem utilizar o sexo como uma base relevante de julgamento para distribuir recompensas e sustentar posições discriminatórias. ${ }^{5}$ Para esse autor, as diferenças de produtividade não decorrem do status sexo, mas sim de motivações socialmente estruturadas, como aquelas que derivam do processo de socialização e do sistema de valores da sociedade. Estes tanto podem induzir as mulheres a se comprometer menos com o trabalho científico - em função da crença nos altos custos sociais da carreira em detrimento da vida familiar -, quanto diminuir sua motivação e torná-las menos produtivas, reforçando a sua identificação com outros grupos de referência em detrimento da comunidade científica. Essa interpretação é matizada por Cole em uma investigação que realizou com Harriet Zuckerman. Conclui com a afirmação de que para a maioria das mulheres a atividade científica e a maternidade não são incompatíveis: mulheres com família publicam, na média, tantos artigos quanto as solteiras. Isso não significa, no entanto, advertem os autores, que casamento e maternidade não produzam efeitos sobre as carreiras das mulheres, mas sim que em geral esses fatores não repercutem em seu desempenho (Cole, Zuckerman, 1991, p.170).

As severas críticas dirigidas a essa abordagem concentram-se no pressuposto que a fundamenta, segundo o qual o sistema meritocrático que governa a ciência distribui recompensas iguais para performances equivalentes, premiando desigualmente desempenhos diferentes. Nessa perspectiva, a ciência constitui uma instituição social universal e neutra em relação a gênero. Outro aspecto criticado, correlacionado ao anterior, é o de que essa abordagem enfatiza demasiadamente as características individuais dos cientistas, em detrimento de fatores coletivos inerentes ao processo de produção de conhecimento. Questionando esse modelo de análise, Bielby (1991) afirma que as diferenças relacionadas a gênero, nas carreiras dos cientistas, se devem a razões de natureza estrutural e cultural mais amplas, bem como ao fato de que a atividade científica é feita em organizações. Ou seja, a ciência não desfruta de um estatuto privilegiado diante das demais profissões; ela 
Luiz Otávio Ferreira et al.

submete-se às regras e aos procedimentos das instituições em que os cientistas trabalham. Nessas, o processo de decisão é inerentemente político, influenciado pela distribuição de poder entre grupos que possuem interesses distintos e, freqüentemente, em conflito. Por conseguinte, conclui: "In short, the course of scientists' careers may be influenced as much or more so by the dynamics of the organization in which they work than by the 'normative principles' or 'goals' of science as an institution" [Em síntese, as carreiras de cientistas podem ser influenciadas tanto ou mais pela dinâmica da organização em que trabalham, do que por 'princípios normativos' ou 'objetivos' da ciência como instituição] (p.177).

Na opinião de Bielby (1991), se os princípios normativos da ciência são relevantes para as escolhas pessoais, os fatores políticos presentes nas instituições são mais decisivos para moldar as carreiras dos cientistas individualmente. A abordagem convencional, que focaliza o indivíduo e enfatiza o princípio normativo da ciência como instituição, promove uma abstração dos modelos de carreira e impede, por conseguinte, a avaliação dos contextos em que eles se estruturam e de sua influência na carreira dos cientistas, nos âmbitos individual e coletivo. Já a perspectiva organizacional propõe examinar as estruturas e os processos que, potencialmente, geram barreiras à eqüidade nas carreiras de homens e mulheres e indaga como as organizações as modelam (p.78, 179, 186).

Orientação similar é sustentada por outros autores, como Epstein (1991). Eles consideram que a análise institucionalista - para a qual as instituições constituem atores políticos em si, não se reduzindo a forças externas, tampouco ao conjunto dos indivíduos que a compõem - é mais adequada do que a abordagem individualista, centrada em fatores como autoseleção e habilidades pessoais, para o estudo dos distintos comportamentos de gênero nas ciências. Essa perspectiva oferece uma explicação melhor a respeito do padrão coletivo de produção de conhecimento de homens e mulheres nos campos disciplinares:

The institutional approach reveals how institutions allocate money, status and power; they have goals, means, resources, boundaries and systems of control ... institutions sometimes have explicit rules governing gender relationships, but they also have organizational cultures in which many gender practices are implicit, often the more powerful for being taken for granted [A abordagem institucional revela como instituições alocam verba, status e poder; elas têm objetivos, significados, recursos, limites e sistemas de controle ... às vezes instituições têm regras explícitas que governam relações de gênero, mas elas também têm culturas organizacionais nas quais muitas práticas relacionadas aos gêneros são implícitas, e em geral são as mais poderosas por serem tidas como certas] (Epstein, 1991, p.244).

Mary Frank Fox (1995, p.219-220) adensa essa corrente interpretativa, chamando a atenção para a sua convergência com a concepção, atualmente dominante na sociologia do conhecimento científico, a respeito da natureza social do conhecimento, além de enfatizar a colaboração entre pesquisadores como um fator relevante para a compreensão das disparidades entre mulheres e homens quanto à produtividade. Como empreendimento interdependente, a ciência envolve o trabalho de equipes e requer vultosos recursos materiais. Por um lado, o desempenho da pesquisa depende do ambiente de trabalho, orientado pelas políticas das instituições, as quais determinam prioridades, salários e posições, encorajando ou impedindo o status e a performance dos cientistas. Sob esse ponto de vista, tais ambientes não operam necessariamente de maneira neutra e uniforme, pois oferecem diferentes 
constrangimentos e oportunidades para cada grupo de gênero. Por outro lado, o desempenho da pesquisa depende também das comunidades disciplinares em que os cientistas se inscrevem, formando redes sociais, simultaneamente formais e informais, e nas quais o conhecimento é verificado e atualizado. A habilidade para construir e manipular uma rede - dentro e fora das organizações de trabalho - constitui um elemento fundamental para a aquisição de prestígio e de poder profissionais e requer a compreensão e a aceitação dos critérios estabelecidos por tradições prévias, a partir das quais uma cultura científica comum é disseminada entre seus membros (p.194, 221). Nesse sentido, a colaboração entre equipes de pesquisadores constitui um aspecto fundamental da produtividade científica das redes sociais da ciência que se aceleraram durante a década de 1950, com a ampliação dos fundos de pesquisa, a especialização das disciplinas e o aprofundamento da profissionalização, conduzindo, entre outros aspectos, a uma reconfiguração das práticas de pesquisa (Fox, 1991, p.197).

Há quatro décadas Price (1969) constatou esse fenômeno, que interligou a aceleração extraordinária da atividade científica após a Segunda Guerra Mundial, traduzida em custos crescentes e na utilização de equipamentos cada vez mais caros e sofisticados, ao aprofundamento da articulação com o sistema econômico. Esse movimento de longa duração da ciência moderna - que descreve a transição, nas palavras do autor, da little science para a big science - se expressa no 'crescimento exponencial' da quantidade de publicações, que, desde o Renascimento, dobra aproximadamente a cada dez ou 15 anos (p.6).

Essa tendência histórica foi acompanhada, em diferentes campos disciplinares, pelo aumento constante da múltipla autoria: se, em 1900, mais de $80 \%$ de todos os artigos científicos tinham apenas um autor, na década de 1960, um em quatro artigos já era escrito por três ou mais autores (Price, 1969, p.89). Paradoxalmente, à medida que aumentou o número de colaborações - com o crescimento contínuo da produtividade dos cientistas mais prolíficos e a ampliação quantitativa desse grupo de autores -, diminuiu o tamanho dos grupos, formados por um pequeno e seleto conjunto de cientistas de, no máximo, cem indivíduos, que buscam o prestígio e o reconhecimento dos pares, bem como a aceitação e a colaboração de colegas ilustres, para os quais dirigem prioritariamente as publicações. Esses grupos, denominados pelo autor de 'colégios invisíveis', mediante os quais o conhecimento se difunde, emergiram para solucionar o problema da comunicação científica a partir do crescimento exponencial da ciência, de que decorreu uma drástica alteração do significado social do artigo científico: a comunicação se faz mais pelo contato pessoal, mediante as colaborações, do que pela publicação (p.83-85). Conforme o autor,

It has made the scientific paper, in many ways an art that is dead or dying. More than this, the invisible colleges have a built-in automatic feedback mechanism that works to increase their strength and power within science and in relation to social and political forces. Worse, the feedback is such that we stand in danger of losing strength and efficiency in fields and countries where the commuting circuit has not yet developed [De muitas formas, fez-se do artigo científico uma arte morta ou em vias de extinção. Mais do que isso, os colégios invisíveis estabeleceram um mecanismo automático de realimentação que aumenta sua força e seu poder dentro do meio científico e na relação com as forças políticas e sociais. Mais do que isso, a realimentação é tamanha que corremos o risco de perder força e eficiência em campos e países nos quais o circuito de trocas ainda não se desenvolveu] (Price, 1969, p.91). 
Essa dinâmica social da ciência, baseada na colaboração, é confirmada por dados mais recentes, segundo os quais, nos periódicos indexados pelo Institute for Scientific Information (ISI), a média do número de autores por artigo saltou de 1,67 para 2,58 entre as décadas de 1960 e 1980, e em certos periódicos e áreas os artigos passaram a ter em média cinco co-autores (Fox, 1991, p.197). Salientada por vários estudiosos, a colaboração constitui uma questão central para que se compreendam as diferenças de gênero em termos de publicações, e constitui um indicador do grau de integração dos cientistas nas comunidades profissionais e, por conseguinte, de sua produtividade. Embora as mulheres sejam tão propensas quanto os homens a executar trabalhos em co-autoria, nota-se que elas não participam de maneira similar à de seus pares masculinos nas redes sociais em que circulam as informações pertinentes à pesquisa. Estas, freqüentemente, ocorrem de modo informal em conversas durante o almoço, nos corredores das instituições e após as reuniões e conferências. Comparada à comunicação formal, a interação face-to-face oferece experiência imprescindível ao progresso das discussões entre colegas a respeito de suas experiências (sucessos e fracassos) de pesquisa. Promove a troca e verificação de idéias e o fortalecimento de interesses comuns (p.194). ${ }^{6}$

Nesse padrão de interação social, a tendência é a marginalização das mulheres, que se mostram menos inclinadas a desenvolver conexões profissionais com editores e referees de periódicos e associações científicas, entre outras modalidade de relações que geram e sustentam a atividade de pesquisa. Para ambos os sexos, a exclusão desses círculos de comunicação, interação e troca restringe o acesso a importantes recursos para fazer pesquisa, publicar e ser citado. Mesmo que não se considerem homens e mulheres como grupos homogêneos separados, com todos os homens dentro e todas as mulheres fora desses colégios invisíveis, constata-se que as mulheres permanecem à margem dos contatos informais em que se estabelecem as colaborações. Enquanto os homens agregam um grande número de colaboradores e colaboram mais amplamente, elas têm mais dificuldade em encontrar pares disponíveis. Colaboram com poucas pessoas, com evidentes prejuízos à produtividade e à performance (Fox, 1991, p.197-198). ${ }^{7}$

Uma outra característica do padrão de publicação feminino é a relevância desempenhada por mentores e maridos em diferentes momentos da carreira (Long, 1992; Fox, 1991, p.221). No início, estudantes produtivos de ambos os sexos são aqueles que estabelecem parceria com seus mentores, e as mulheres são as que mais publicam artigos nessa modalidade de colaboração (Long, 1992). Verifica-se que esse contato produz outros efeitos sobre a futura colocação profissional e a produtividade científica. Com o aumento da maturidade intelectual esse tipo de colaboração é substituído pelos colegas, estudantes e maridos. Quanto a estes últimos, as diferenças são expressivas: se entre os homens somente de 1 a $2 \%$ colaboram com o cônjuge, entre as mulheres esse percentual é de 10\%. Outro dado significativo é que mulheres são mais propensas a casar com outro cientista. É significativa a proporção das que colaboram com os esposos, ao passo que poucos homens estabelecem essa forma de colaboração (p.169). ${ }^{8}$

Longe de encerrarem a polêmica em torno das diferenças de produtividade das mulheres vis-à-vis seus pares homens, esses estudos oferecem elementos importantes para a compreensão dessa questão, sobretudo ao relativizar características pessoais como habilidade, 
casamento e maternidade e relevar a dimensão institucional da atividade científica no que diz respeito aos condicionamentos impostos pelo ambiente de trabalho e pelas comunidades disciplinares. As condições práticas e as relações político-científicas desses contextos institucionais - que determinam o status e a performance individual dos cientistas - constituem indicações mais seguras para que se compreenda o padrão de exclusão ou inclusão de homens e mulheres, em particular no que concerne às diferenças de produtividade entre ambos.

Essa linha de argumentação informou, em larga medida, a análise que empreendemos sobre uma parcela da produção científica feminina ao longo de três décadas, em que a comparamos com a da sua contraparte masculina. Para tanto, relacionamos essa produção às condições históricas e sociais que levaram à crescente educação feminina a partir da década de 1930, em particular a de nível superior. Se esse fenômeno de amplas repercussões sociais produziu efeitos imediatos sobre as recém-criadas universidades na capital federal e na cidade de São Paulo, interferiu também, de modo inesperado e com conseqüências duradouras, no processo de institucionalização da ciência no país.

\section{A experiência da educação e profissionalização científica das mulheres}

O estudo das relações de gênero na institucionalização da comunidade científica brasileira torna-se relevante quando se constata o acelerado e vigoroso ingresso de mulheres em todos os níveis de ensino a partir da década de 1940, processo que conduzirá à preeminência, a partir de 1970, das mulheres em termos de escolaridade (Beltrão, Alves, 2004).

No caso específico do ensino superior, a mudança dos padrões de acesso, até então totalmente favoráveis aos homens, foi proporcionada, em larga medida, pela concomitância não deliberada de políticas públicas, que tornaram possíveis as experiências pioneiras de formação para o magistério em curso de nível superior, a expansão da rede pública e privada de ensino secundário e, finalmente, a proliferação pelo país de faculdades de filosofia, ciências e letras, inspiradas no modelo estabelecido na Universidade de São Paulo (USP), criada em 1934, e na Universidade de Distrito Federal (UDF), fundada em 1935 e, em 1939, incorporada à Universidade do Brasil (UB). ${ }^{9}$ Esse processo de expansão da presença feminina nas universidades culminou com a reforma universitária no final dos anos 60, quando os cursos profissionalizantes - incluindo o curso normal - foram reconhecidos como cursos secundários aptos ao ingresso direto na universidade, por meio do vestibular.

A reorganização do ensino superior brasileiro, ocasionada pela adoção do modelo universitário, inaugurou uma nova fase da institucionalização das ciências, com lentas mas importantes conseqüências sobre esse processo. Na década de 1920, a questão universitária ressurgiu com uma conotação distinta daquela que predominou entre o final do Império e o início da República. Do ponto de vista dos intelectuais comprometidos com as reformas da educação - articulados na Associação Brasileira de Educação, criada em 1923, entre os quais se incluíam as principais lideranças científicas, vinculadas à Academia Brasileira de Ciências, fundada em 1922 -, não se tratava mais de substituir apenas o modelo institucional e pedagógico das escolas e faculdades profissionalizantes - considerado anacrônico e comprometido ideologicamente com os interesses do regime monárquico 
Luiz Otávio Ferreira et al.

(Barros, 1986; Cunha, 1980) -, mas sim de construir um moderno sistema escolar no país, do qual a universidade representaria o ápice.

Mas, se havia um consenso quanto à necessidade de sua implantação, a divergência predominava no que dizia respeito ao formato a ser adotado, evidenciando diferentes projetos que traduziam interesses específicos a respeito das funções sociais atribuídas ao ensino superior. As opiniões oscilavam entre a defesa de uma universidade voltada exclusivamente para a produção de conhecimento científico e o posicionamento a favor de uma universidade direcionada à produção de conhecimento técnico e aplicado à resolução de problemas nacionais (Carvalho, 1998, p.258-276; Mendonça, maio-ago. 2000, p.137).

Embora se atribua aos cientistas um peso decisivo na conformação do modelo de universidade adotado no país (Paim, 1982), nota-se que o ambiente político e intelectual que deu origem a essas universidades foi dominado pelos chamados 'educadores profissionais', genericamente identificados com o movimento pela 'escola nova'. É esse o caso de São Paulo, em que tais educadores não apenas participaram ativamente das disputas para controlar o sistema de ensino desde o início da década de 1920, em meio às reformas promovidas pelo governo do Estado, como também se engajaram nos debates sobre a implantação da universidade - liderados por Júlio de Mesquita Filho, proprietário e editor do jornal O Estado de S. Paulo, que personificava as elites políticas locais -, ao perceberem uma oportunidade para institucionalizar suas idéias (Limongi, 1989, p.128-157).

Inicialmente, a universidade imaginada pelos educadores profissionais paulistas compreendia uma faculdade de filosofia, educação e letras - de inspiração francesa - que serviria ao aperfeiçoamento pedagógico e cultural dos docentes e à formação de quadros para a burocracia do sistema escolar, orientação que seria enfatizada por Fernando Azevedo em seu discurso de posse como diretor da Faculdade de Filosofia, Ciências e Letras (FFCL) da USP em 1941:

mas não é somente o desenvolvimento dos estudos literários e científicos, desinteressados, que à Faculdade de Filosofia está reservado um papel de primeira ordem na Universidade de São Paulo. Ela é chamada, como todas as outras escolas similares, a exercer uma missão tão urgente quanto relevante, essencial a educação dos adolescentes: a formação do professorado secundário. É esta, no seu plano de estudos, a única finalidade profissional. (Azevedo, 1941, p.37)

A referência de Fernando Azevedo aos estudos literários e científicos desinteressados diz respeito às disputas em torno da função social da universidade, como mencionado anteriormente, as quais envolviam os educadores profissionais, como o próprio Azevedo, e a comunidade científica. A querela se desenvolveu em torno da divisão entre os adeptos das faculdades voltadas à formação profissional e à produção de conhecimento aplicado, de um lado, e os defensores das faculdades orientadas para a produção de conhecimento desinteressado e a formação de cientistas, de outro, e o modelo adotado na USP, segundo o qual a FFCL constitui a 'célula mater' (Schwartzman, 1979, p.197), representou uma conciliação dessas posições. No entanto, ressalve-se que essa solução arranjada pelos educadores profissionais significou a criação de um centro de poder sob seu controle, que transferiu para segundo plano os interesses da comunidade científica. Além disso, a concepção dos cientistas, de que a Faculdade de Filosofia deveria funcionar como um 
centro de produção de conhecimento, esbarrou nas limitações do próprio modelo adotado. Do ponto de vista da organização do trabalho científico, o modelo de inspiração francesa já estava à época defasado, sobretudo por não se basear na dedicação integral e exclusiva dos docentes às atividades de ensino e pesquisa, tal como ocorria nas universidades norteamericanas e inglesas. Além disso, esse modelo favorecia o desequilíbrio entre a atenção dada às ciências humanas aplicadas - fundada na idéia da educação como fator de mudança social - e às ciências naturais, uma conseqüência óbvia do controle institucional exercido pelos educadores profissionais, quase todos normalistas, intelectuais treinados segundo os paradigmas da sociologia, pedagogia e psicologia. A configuração das faculdades nesses termos, de que a USP e a UB são emblemáticas, manterá a comunidade científica mobilizada, daí em diante, em torno da defesa de um status diferenciado para a pesquisa e o ensino científicos no conjunto das atribuições universitárias.

Porém a supremacia dos educadores nessa disputa favoreceu a incorporação de mulheres ao ensino superior. Os jovens (homens) oriundos das elites e da classe média - que se dirigiam habitualmente às tradicionais faculdades profissionais, em busca dos diplomas que lhes garantissem sustentação econômica e prestígio social condizente com os papéis sociais de gênero vigentes - não se sensibilizaram com a convocação para a formação e a profissionalização com as características dadas no projeto dos educadores profissionais. No caso da USP, a solução encontrada para contornar a baixa capacidade de recrutamento masculino para a Faculdade de Filosofia foi a convocação dos 'normalistas' professores da rede estadual de ensino, o que se converteu em uma oportunidade ímpar e pioneira para o ingresso de mulheres ao curso superior (Limongi, 1989, p.160; Schwartzman, 1979, p.211).

\section{O ingresso de mulheres nas faculdades de filosofia}

$\mathrm{O}$ afluxo crescente e maciço de mulheres às faculdades de filosofia tem sido interpretado como uma decorrência da abstenção masculina, bem como do suposto caráter não profissionalizante de seus cursos (Trigo, 1994, p.94). A nosso ver, sua presença significativa ali pode ser relacionada à própria dinâmica do processo de modernização em curso, notadamente no que diz respeito ao mercado de trabalho (Azevedo, Ferreira, 2006). Na ausência de um sistema de ensino secundário institucionalizado, os portadores do diploma emitido pela escola normal, freqüentada em sua maioria por mulheres, constituíam o único contingente populacional capacitado para atender à demanda de quadros exigidos pelo crescimento do aparelho estatal e da economia urbana. A "versatilidade ocupacional e intelectual" do "normalista" (Limongi, 1989, p.136) habilitou um expressivo número de professoras, que já haviam adquirido o nível de escolaridade e o treinamento institucional necessários, a compor não somente as turmas dos cursos de ciências e humanidades oferecidos nas faculdades de filosofia, mas também os cursos de enfermagem, educação sanitária e serviço social, que se institucionalizaram na mesma época (Faria, jul.-dez. 2006, 2007). ${ }^{10}$

A transformação das faculdades de filosofia em instituições que favoreceram a participação das mulheres na esfera pública dirigiu decisivamente a aplicação social do conhecimento, sobretudo em atividades relacionadas ao magistério e outras atividades pedagógicas. Essas instituições contribuíram para a superação de um padrão de recrutamento 
que, a priori, excluía as mulheres das profissões de nível superior. Embora desde 1879, com a reforma do ensino empreendida pelo ministro dos Negócios do Império Leôncio de Carvalho, as mulheres tivessem sido autorizadas a freqüentar os cursos de nível superior, elas enfrentaram severas barreiras morais e intelectuais, decorrentes da cultura dominante nas tradicionais faculdades e escolas profissionais, concebidas como espaços destinados à educação masculina. Nesse sentido, até o início do funcionamento das faculdades de filosofia, o regime de co-educação, na prática, não existia nessas instituições, e nelas a participação feminina se restringia a casos esporádicos. Houve a presença de pioneiras em certas profissões ou atividades acadêmicas (Rago, 2000, abr.-jun. 2002), fato que, embora relevante, não produziu alterações institucionais mais amplas do ponto de vista de gênero.

O caráter inovador desse padrão de recrutamento refletia os efeitos do processo de modernização, que incidiram sobretudo nas principais metrópoles brasileiras. Predominantemente oriunda da classe média, a composição da clientela das faculdades de filosofia correspondeu, em larga medida, às características sociodemográficas desse processo, e a presença expressiva de mulheres tornou-se uma característica institucional comum à maioria delas. Outro aspecto sociologicamente relevante, constatado nas faculdades de filosofia da USP e da UB, é a participação dos filhos de imigrantes europeus, contingente populacional crescente e com marcada relevância na vida urbana durante a primeira metade do século XX (Hutchinson, dez. 1956, mar. 1957; Sevcenko, 1992, 1998). ${ }^{11}$ Nota-se, nesse sentido, o início da transformação do perfil social dos cientistas, cujas primeiras gerações constituíam um grupo reduzido e extraído das elites econômicas, políticas e intelectuais, para o qual o background familiar constituía influência decisiva na formação dos destinos individuais (Schwartzman, 2001). ${ }^{12}$

A percepção de que o ingresso maciço de mulheres alterou profundamente o papel institucional inicialmente projetado para as faculdades de filosofia constitui, possivelmente, um dos motivos que levaram a coletividade científica atuante nas décadas de 1950 e 1960 a se engajar na reforma do ensino superior, que ocorreu em 1968 e redundou na extinção das mais de setenta faculdades de filosofia em funcionamento no país. Na avaliação das principais lideranças científicas e educacionais - representadas, por exemplo, na Sociedade Brasileira Para o Progresso da Ciência (SPBC), no Conselho Federal de Educação (CFE) e no Instituto Nacional de Estudos Pedagógicos (Inep) -, a organização e o funcionamento dessas instituições eram precários e destoantes em relação a um dos seus principais propósitos: a formação de cientistas e a produção de conhecimento. A 'crise' da faculdades de filosofia foi motivo para a realização, em 1961, do Simpósio sobre a Estrutura da Faculdades de Filosofia, no qual se estabeleceu consenso a respeito da necessidade de abandonar o modelo de organização universitária nucleada pela faculdades de filosofia (Fernandes, 2000; Celeste Filho, jan.-jun. 2004).

A idéia de 'crise' generalizada se propagou a partir de uma avaliação a respeito da Faculdade de Filosofia Ciências e Letras da USP, elaborada após manifestações de protesto de professores e alunos em 1958, nas quais se reivindicava a atenção das autoridades universitárias para os problemas percebidos no funcionamento administrativo e no desempenho acadêmico daquela faculdade. Em denso relatório, o titular da cadeira de sociologia, Florestan Fernandes (1966), estabelecia uma relação entre a 'crise' e os efeitos institucionais decorrentes da 
presença expressiva de mulheres na composição do corpo discente, situando o problema na incapacidade de recrutamento de candidatos genuinamente vocacionados para a pesquisa. As oportunidades profissionais pouco atraentes oferecidas a bacharéis e a licenciados - não traduzidas "em compensações monetárias e de prestígio ... essenciais em uma sociedade competitiva e individualista" - criavam, segundo ele, "um circulo vicioso intransponível", que acarretava o recrutamento de alunos intelectualmente despreparados e/ou sem interesse nas carreiras para as quais seriam treinados (p.263).

Essa análise, aparentemente neutra, é concluída com uma apreciação a respeito do significado do gênero na conformação da Faculdade de Filosofia, Ciências e Letras da USP e - por que não? - das faculdades de filosofia em geral:

\begin{abstract}
Esse processo apresenta certa similaridade com o que sucedeu com nossas escolas normais, que se transformaram em centros de disseminação de 'cultura geral', em diferentes tipos de comunidades brasileiras. Há defensores entusiastas desse processo entre nossos professores. Alega-se que ele alarga o grau de participação da mulher no ensino superior. Todavia, parece que não se deve confundir coisas distintas. Não nos importa o sexo dos candidatos aos cursos devemos ter em conta somente suas aptidões intelectuais e as perspectivas que oferecem de realização das carreiras implicitamente escolhidas. Deste ângulo, nenhum interesse ponderável justifica que uma instrução deveras custosa seja dispensada a candidatos que não aspirem tirar proveito dela para si e a para coletividade. (Fernandes, 1966, p.263-264; grifo nosso)
\end{abstract}

A avaliação do influente sociólogo a respeito da Faculdade de Filosofia, baseada inequivocamente em uma distinção de gênero, é notavelmente esclarecedora da percepção e da posição assumida pela 'comunidade científica' no debate sobre a reforma do ensino superior, em que se defendia a substituição das faculdades de filosofia por institutos de ciências - estes sim, argumentavam, capazes de cumprir o modelo originalmente para elas idealizado.

As faculdades de filosofia e o acesso de mulheres à comunidade científica

$\mathrm{Na}$ investigação que vimos desenvolvendo sobre a Faculdade Nacional de Filosofia (FNFi) da UB ${ }^{13}$, constatamos que, entre 1940 e 1960, as mulheres constituíram, aproximadamente, $70 \%$ dos diplomados. Já no curso de história natural da Faculdade de Filosofia, Ciências e Letras da USP, 74\% dos diplomados, entre 1937 e 1969, pertenciam ao sexo feminino. Fenômeno similar foi constatado por Pereira (dez. 2000) na Faculdade de Filosofia da Universidade de Minas Gerais, em que, no mesmo período, mais da metade dos diplomados eram mulheres.

Contudo a intensificação da presença feminina na comunidade científica brasileira, proporcionada pela superioridade numérica das mulheres nas faculdades de filosofia, constitui um fenômeno que se deve examinar com cuidado. Note-se que a carreira acadêmica era, para as mulheres, um dos destinos profissionais possíveis, e não necessariamente o mais interessante e desejado (Azevedo, Ferreira, 2006). O magistério e outras ocupações pedagógicas se apresentavam como destinos profissionais mais atraentes e promissores, não por se delinearem socialmente como profissões eminentemente femininas, como habitualmente se interpreta, mas sim em virtude do baixo grau de profissionalização da atividade científica. Esta não constituía, como o magistério, uma profissão plenamente institucionalizada, com acesso amplo e carreira estabelecida. ${ }^{14}$ Dessa maneira, a superioridade 
Luiz Otávio Ferreira et al.

numérica de mulheres nas faculdades de filosofia, especialmente nos cursos de ciências naturais e exatas, não alterou imediata e automaticamente a composição predominantemente masculina do mundo das ciências. A maioria das que ali se formaram optou pelo magistério, e aquelas que se direcionaram para a pesquisa científica tenderam a combiná-la com a atividade do magistério de ensino secundário e superior, traço comum em suas trajetórias profissionais (Azevedo et al., dez. 2004). ${ }^{15}$

Outro aspecto a ressaltar é o da posição ocupada pelas mulheres nas hierarquias científicas, naquele momento. Embora as egressas das faculdades de filosofia tenham contribuído para o aumento da comunidade científica, ainda prevalecia no heterogêneo conjunto das instituições um princípio rígido de autoridade científica, centrado exclusivamente nas figuras masculinas do professor catedrático e/ou do pesquisador de indiscutível prestígio. Mesmo nas faculdades de filosofia que se apresentavam como uma inovação institucional, adotou-se o tradicional regime de cátedras. Mas se tal estratificação não favorecia a incorporação de mulheres aos laboratórios de pesquisa, também não a inibiu. Elas contribuíram para a renovação institucional e disciplinar de vários campos, como física, matemática, química, geologia e genética, figurando uma situação de interdependência entre institucionalização da ciência e gênero. Um caso emblemático dessa interdependência é o do Instituto de Matemática e Física da Faculdade de Filosofia, Ciências e Letras da Universidade da Bahia, fundado por mulheres, no qual elas predominaram na composição do corpo docente e discente (Dias, nov. 2000-fev. 2001). A criação desse e de outros cursos congêneres em diversas regiões do país interrompeu o antigo vínculo dessas disciplinas com as faculdades de engenharia, possibilitando um importante movimento de renovação teórica, bem como uma virtual 'desmasculinação' da matemática e da física no mundo acadêmico brasileiro. Tais áreas passaram a adquirir um novo status científico e social.

As marcas das contribuições femininas ao desenvolvimento científico podem ser detectadas nas revistas científicas da época, das quais descrevemos brevemente, a seguir, o perfil editorial.

\section{As características institucionais dos periódicos científicos}

Um traço comum ao conjunto dos periódicos científicos brasileiros em circulação no período em análise foi a sua incipiente institucionalização. A criação e a manutenção desses periódicos, na maioria das vezes, eram parte da estratégia de consolidação de entidades científicas tais como institutos de pesquisa e de ensino superior, sociedades científicas e órgãos públicos com atribuições relacionadas a atividades tecnocientíficas. Para os dirigentes dessas instituições, os periódicos se apresentavam como um meio não só de divulgação de atividades, mas também de mobilização de agentes sociais que poderiam ser aliados importantes no esforço de legitimação político-social de suas ações. Os quatro periódicos científicos selecionados - Anais da Academia Brasileira de Ciências, Revista Brasileira de Biologia, Memórias do Instituto Oswaldo Cruz e Revista Brasileira de Malariologia e Doenças Tropicais constituem, de algum modo, exemplos dessa dependência, por entrelaçacem sua trajetória à história de seus patrocinadores. ${ }^{16}$ 


\section{Memórias do Instituto Oswaldo Cruz}

O mais antigos desses periódicos, as Memórias do Instituto Oswaldo Cruz, cujo primeiro número foi lançado em abril de 1909, se apresenta como uma típica revista institucional, cujo propósito principal, evidenciado no próprio título, é o de registrar a produção científica engendrada no Instituto. Como órgão oficial do Instituto Oswaldo Cruz (IOC), a revista se caracterizou desde o início como uma publicação endógena, uma vez que, conforme as regras estabelecidas pela instituição, publicava apenas trabalhos originais cujos autores pertencessem ao quadro de pesquisadores da instituição, orientação que permaneceu inalterada até 1980. Outra peculiaridade reside no formato de seus textos, quase sempre muito extensos e exigentes de recursos tipográficos, fugindo ao padrão habitual de outros periódicos, nos quais dificilmente seriam publicados (Briquet de Lemos, abr.-jun. 1993).

Para a análise da produção científica que aqui pretendemos desenvolver, o caráter institucional dessa revista traz implicações evidentes. Se, do ponto de vista da produção do conhecimento biomédico, constitui uma fonte indiscutivelmente relevante, não revela o mesmo valor para identificação da posição feminina na comunidade científica. Oferece um ponto de observação restrito porque limitado ao universo de pesquisadoras do quadro funcional do IOC, que, sabemos, representava um contingente de pequenas proporções: até 1970 apenas 18 mulheres haviam sido efetivadas como pesquisadoras. ${ }^{17}$

\section{Revista Brasileira de Malariologia e Doenças Tropicais}

A mesma característica de periódico institucional pode ser aplicada à Revista Brasileira de Malariologia e Doenças Tropicais, cujo primeiro número circulou em janeiro de 1949. Como órgão oficial do Serviço Nacional de Malária do Ministério da Educação e Saúde, ela foi concebida como veículo de divulgação da ciência aplicada, "mais prática do que teórica e inteiramente estranha ao espírito acadêmico" (Pinotti, jan. 1949, p.1), a serviço da interação, informação e comunicação entre os "técnicos em malariologia".

Embora a revista aceitasse contribuição de colaboradores não vinculados ao Serviço Nacional de Malária, a maioria dos autores pertencia ao seu quadro funcional e ao Instituto Nacional de Endemias Rurais, instituição também vinculada ao Ministério da Saúde, tendendo, em larga medida, à endogenia e à publicação de um universo restrito de autores, especialistas em doenças tropicais (médicos e sanitaristas), em geral do sexo masculino (Cunha, 2005; Castro Santos, Faria, set. 2006).

\section{Revista Brasileira de Biologia}

Editada desde 1940, a Revista Brasileira de Biologia vinculava-se à Sociedade Brasileira de Biologia, entidade que desde a década de 1920 funcionava como uma espécie de filial brasileira da Sociedade de Biologia de Paris. Com a eclosão da Segunda Guerra Mundial interrompeu-se esse intercâmbio, e os biólogos brasileiros se viram privados de um importante meio para divulgação de seus trabalhos, o Compte Rendu de la Societé de Biologie. Sediada no Rio de Janeiro e financiada com recursos concedidos pelo empresário Guilherme Guinle, e mais tarde pelo CNPq, a Revista Brasileira de Biologia foi dirigida por pesquisadores da Divisão de Zoologia Médica do IOC. 
Seus objetivos eram ao mesmo tempo institucionais e científicos: estimular a criação de novas seções regionais da Sociedade e publicar trabalhos do vasto campo do conhecimento biológico e biomédico, o que incluiu: micro e macro-anatomia, fisiologia vegetal e animal, patologia, bacteriologia, parasitologia, imunologia, genética, bioquímica, farmacologia, zoologia descritiva e experimental, botânica e biologia geral. O amplo espectro disciplinar coberto por essa revista, de certo modo, anulou a tendência a transformá-lo em um outro periódico exclusivo do IOC, tendência esta decorrente do fato de seu conselho editorial ter sido sempre composto por cientistas daquela instituição. Pode-se dizer que ela funcionou como uma rede social ao estilo dos 'colégios invisíveis', articulando pesquisadores de diversas instituições nacionais interessados em dar visibilidade a um tipo de produção científica para a qual não havia muitos canais de difusão disponíveis. Essa rede reunia, além de instituições científicas tradicionais como o IOC e o Instituto Biológico de São Paulo redutos masculinos da biomedicina e da biologia experimental e aplicada -, novas instituições científicas, representadas pelas faculdades de filosofia, principalmente de São Paulo, Rio de Janeiro e Minas Gerais, bem como a Faculdade de Higiene e Saúde Pública da USP, nas quais novas tradições disciplinares no campo biológico e biomédico floresciam simultaneamente e um contingente feminino crescente se incorporava.

\section{Anais da Academia Brasileira de Ciências}

Como sabemos, a Academia Brasileira de Ciências reuniu uma parcela da comunidade científica brasileira interessada em promover a 'ciência pura' de alto nível no país. Ela não tinha programas próprios de pesquisa, e se constituiu como um reduto de resistência à concepção utilitarista e positivista das ciências, abrigada na Escola Politécnica do Rio de Janeiro (Pauliny, 1981, p.164). Nesse sentido, liderou a luta pela institucionalização da universidade, cuja função precípua seria a de implantar a pesquisa científica desinteressada, isto é, sem compromissos imediatos com qualquer tipo de aplicação tecnológica ou social (Paim, 1982, p.30-36).

Até 1929 as publicações da Academia (sucessivamente denominadas Revista da Sociedade Brasileira de Ciências, Revista de Ciências, Revista da Academia Brasileira de Ciências e, finalmente, Anais da Academia Brasileira de Ciências) tiveram periodicidade irregular manifestando a precariedade institucional típica das revistas científicas nacionais da época - e se restringiam a comunicações e artigos do restrito grupo dos associados que, em 1942, somavam 69 cientistas, todos do sexo masculino. Somente no final da década de 1940 a revista se abriu à contribuição de cientistas externos à instituição, sobretudo aqueles vinculados às faculdades de filosofia, de onde emergiram novos grupos de pesquisa nos quais figuravam mulheres. Desse modo, cumprindo papel semelhante ao da Revista Brasileira de Biologia, os Anais abrigariam tanto a produção científica de áreas já tradicionais, tais como a história natural taxonômica, a geologia de tipo exploratório ou a microbiologia pastoriana, quanto a produção científica de áreas emergentes, como a física nuclear, a química experimental e a genética.

Essa breve síntese das características desses quatro periódicos sugere uma aproximação entre os Anais da Academia Brasileira de Ciências e a Revista Brasileira de Biologia e uma distinção em relação às duas outras. Ainda que as duas primeiras possam ser classificadas 
também como revistas institucionais, destacam-se pela linha editorial abrangente, acompanhando a dinâmica da produção científica em seus aspectos disciplinares, institucionais e de gênero e fugindo às tendências endógenas e restritivas a certos campos de especialização disciplinar que marcaram as Memórias do Instituto Oswaldo Cruz e a Revista Brasileira de Malariologia e Doenças Tropicais. Em larga medida, como veremos a seguir, tais características e distinções presentes nesses periódicos refletem e até certo ponto explicam as diferenças constatadas entre homens e mulheres no padrão de publicação.

\section{As publicações científicas como índice de inclusão das mulheres nas ciências}

A produção científica constitui um objeto de análise relevante para aferir o grau de inserção das mulheres na comunidade científica. Promove a aproximação preliminar da natureza do processo de institucionalização, bem como das influências que nele exerceram e sofreram as mulheres em suas trajetórias profissionais.

Nosso ponto de partida foi a estruturação de um banco de dados, que tem como unidade de análise os artigos publicados entre 1939 e 1969 nos periódicos selecionados, referentes aos campos da saúde pública e das ciências biomédicas, exatas e da natureza. Inicialmente, esse banco foi organizado apenas com os artigos nos quais se identificou alguma autoria feminina, individual ou em co-autoria. No entanto, à medida que começamos a descrever os dados coligidos, evidenciou-se a necessidade de comparar essa produção com aquela exclusivamente masculina, que conforma a ampla maioria dos artigos publicados nesses periódicos.

Outro aspecto importante foi a dificuldade de identificar as áreas de inscrição disciplinar dos autores, visto que as regras editoriais da época não exigiam a inclusão de palavraschave e de resumos a respeito do teor dos artigos. Eliminou-se, portanto, essa dimensão da análise realizada. Ressalte-se ainda que o universo total de registros é composto por 5.051 artigos, distribuídos por sexo do autor/autora, da seguinte maneira: 4.278 artigos (84\%) de autoria exclusivamente masculina, e 773 artigos (16\%) com alguma autoria feminina. Destes últimos, 271 são artigos individuais de autoria feminina, correspondendo a $35 \%$ dos artigos com alguma autoria feminina, e a 5,3\% do universo total de artigos.

De modo a identificar os padrões e as tendências na dinâmica das publicações, capazes de revelar diferenças e similaridades entre homens e mulheres, elegemos quatro variáveis principais, escrutinadas por ano e revista, a saber: total do número de artigos; razão do número de artigos femininos sobre os masculinos; distribuição relativa do número de autores por artigo; distribuição dos artigos femininos escritos individualmente, em relação ao universo total de artigos com alguma autoria feminina; e distribuição relativa do vínculo institucional do primeiro autor.

Uma primeira observação de caráter geral diz respeito à evolução das publicações anuais em cada periódico, sobressaindo a inconstância do número de artigos publicados por década, como mostra o Gráfico 1.

A maior ou menor oscilação constitui um traço comum a todas as revistas analisadas, embora constatemos certa regularidade na publicação de quatro edições anuais, exceto as Memórias do Instituto Oswaldo Cruz: entre 1943 e 1945, o número de edições duplicou, e a partir de 1950, raramente a quarta edição foi publicada; alternaram-se, a partir de então, 
Gráfico 1

Número de artigos publicados por ano em cada um dos periódicos

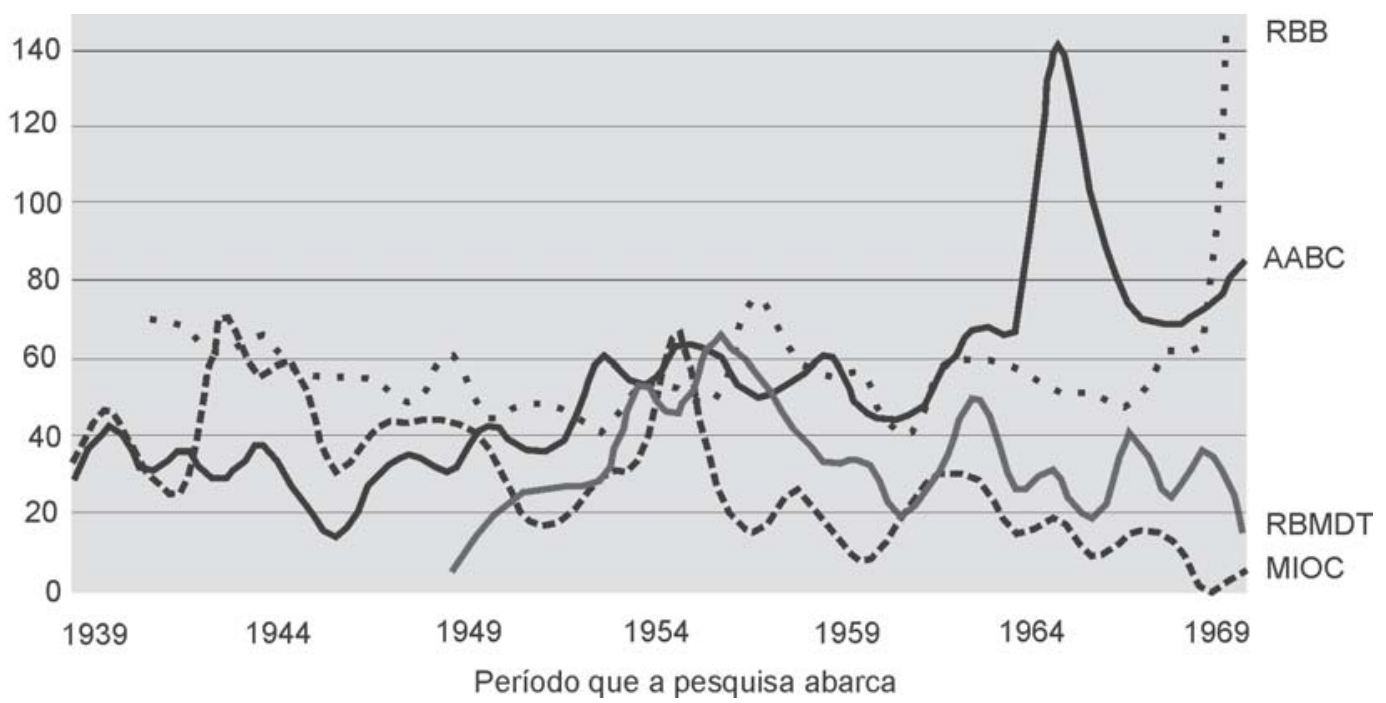

uma ou duas edições por ano. ${ }^{18}$ Porém verifica-se que a Revista Brasileira de Biologia - que apresenta o menor índice de variação no formato editorial - e os Anais da Academia Brasileira de Ciências tiveram um claro crescimento quantitativo de artigos durante a década de 1960. Movimento inverso nota-se nas Memórias do Instituto Oswaldo Cruz e na Revista Brasileira Malariologia e Doenças Tropicais $^{19}$, que mergulharam nesse mesmo período em um lento declínio. É provável, pelo menos no que diz respeito às Memórias do Instituto Oswaldo Cruz, que tal tendência reflita a instabilidade político-administrativa do Instituto Oswaldo Cruz, decorrente da crise ali gerada pelo golpe militar de 1964, que culminou com a demissão e cassação dos direitos políticos de vários pesquisadores (Hamilton, 1989). Por sua vez, a Revista Brasileira de Malariologia e Doenças Tropicais teve sua sobrevivência comprometida, possivelmente, pela concorrência de um periódico com perfil similar, a Revista da Sociedade Brasileira de Medicina Tropical2 ${ }^{20}$, que surgiu em 1968.

Com o intuito de melhor avaliar a produção feminina vis-à-vis a masculina, consideramos adequado não estabelecer uma medida baseada simplesmente em percentuais, uma vez que a totalidade de artigos varia intensamente entre 1939 e 1969, e um mesmo percentual poderia significar números absolutos muito distintos, dependendo do ano. Tomando como parâmetro de análise a totalidade da produção exclusivamente masculina, usamos a razão como uma medida relacional capaz de capturar a variação dos artigos com alguma autoria feminina no período. Considerando que a razão 1 corresponde a total equivalência de artigos femininos e masculinos, o Gráfico 2 demonstra, em linhas gerais, que as curvas raramente superam o patamar da razão 0,4 . Isso indica que os artigos com alguma autoria feminina não alcançam a metade da produção masculina na maior parte das três décadas.

Comparando os Gráficos 1 e 2, percebe-se que o aumento do peso das autorias femininas não esteve atrelado historicamente ao crescimento total de publicações das revistas, embora sua participação tenha aumentado em todas as revistas no período analisado. Porém o 
Gráfico 2 evidencia uma tendência ascendente das razões de artigos femininos, sobretudo na Revista Brasileira de Biologia e nos Anais da Academia Brasileira de Ciências, uma vez que ambos publicaram um conjunto maior de artigos. Ressalte-se que as variações intensas nas Memórias do Instituto Oswaldo Cruz e na Revista Brasileira de Malariologia e Doenças Tropicais refletem uma amostra muito reduzida, particularmente a partir dos anos 60, não representativa da produção acadêmica, o que levou à sua exclusão das análises seguintes.

Gráfico 2

Razão de artigos femininos sobre os masculinos nos quatro periódicos

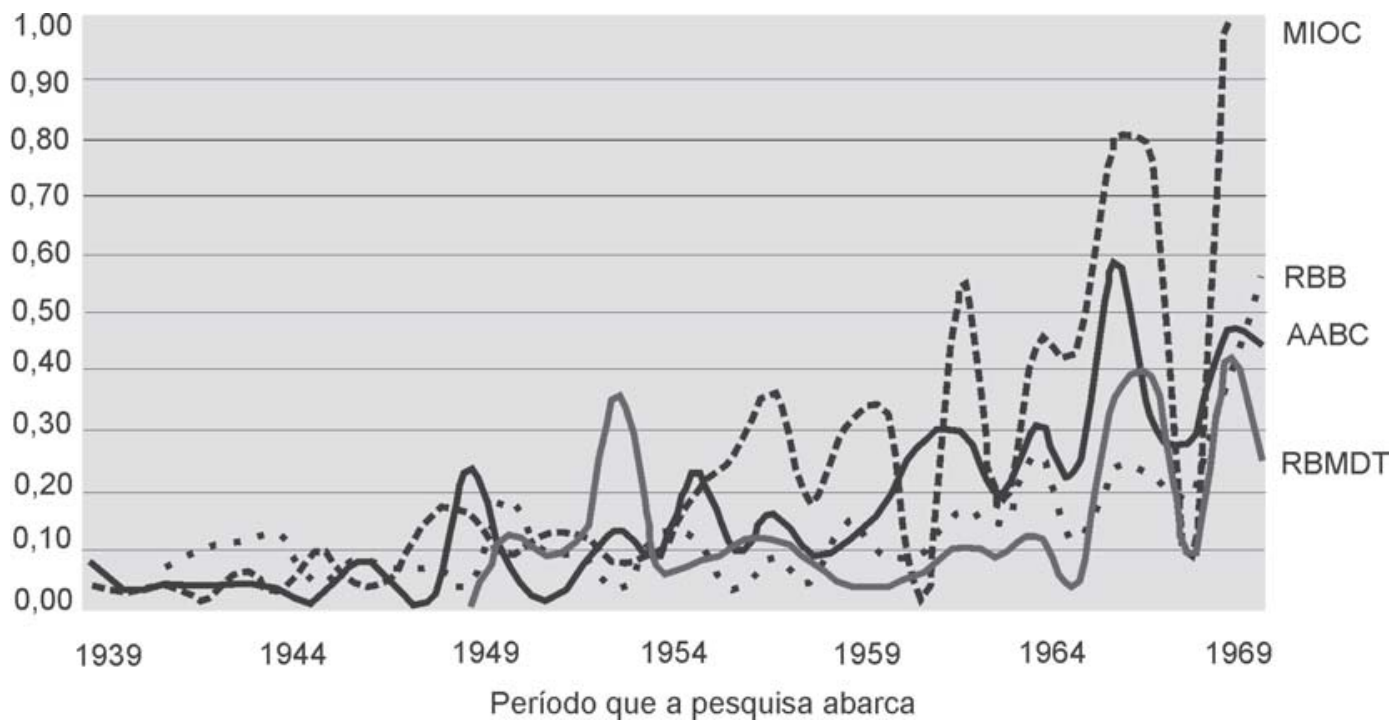

Outro aspecto é revelado nos Gráficos 3 e 4, que mostram a distribuição do número de autores dos grupos de artigos exclusivamente escritos por homens e dos artigos nos quais se identifica alguma autoria feminina. ${ }^{21}$ Evidencia-se uma tendência crescente nos artigos com alguma autoria feminina, sugerindo uma inserção efetiva de mulheres nas comunidades disciplinares que divulgavam sua produção científica na Revista Brasileira de Biologia e nos Anais da Academia Brasileira de Ciências.

Nota-se ainda que os artigos individuais têm maior peso no conjunto da produção exclusivamente masculina, ao passo que os artigos com alguma autoria feminina mostram clara propensão ao aumento da publicação em equipes, perdendo peso não apenas os artigos individuais, mas também aqueles com dois autores. Além disso, nos artigos exclusivamente masculinos mantém-se, de modo consistente, uma distribuição percentual notavelmente elevada dos artigos individuais.

A natureza dessa distinção entre os grupos de autores, de certo modo surpreendente, reflete, a nosso ver, a organização universitária baseada na cátedra. Como mencionado anteriormente, a cátedra se estruturava em torno de um notável, geralmente uma figura masculina, e seus assistentes. Esse modelo de organização e hierarquização do trabalho científico, também vigente nas instituições de pesquisa mesmo sem essa denominação, restringia as oportunidades profissionais daqueles que percebiam no ambiente acadêmico 
Gráfico 3

Distribuição do número de autores por artigo na Revista Brasileira de Biologia, por década

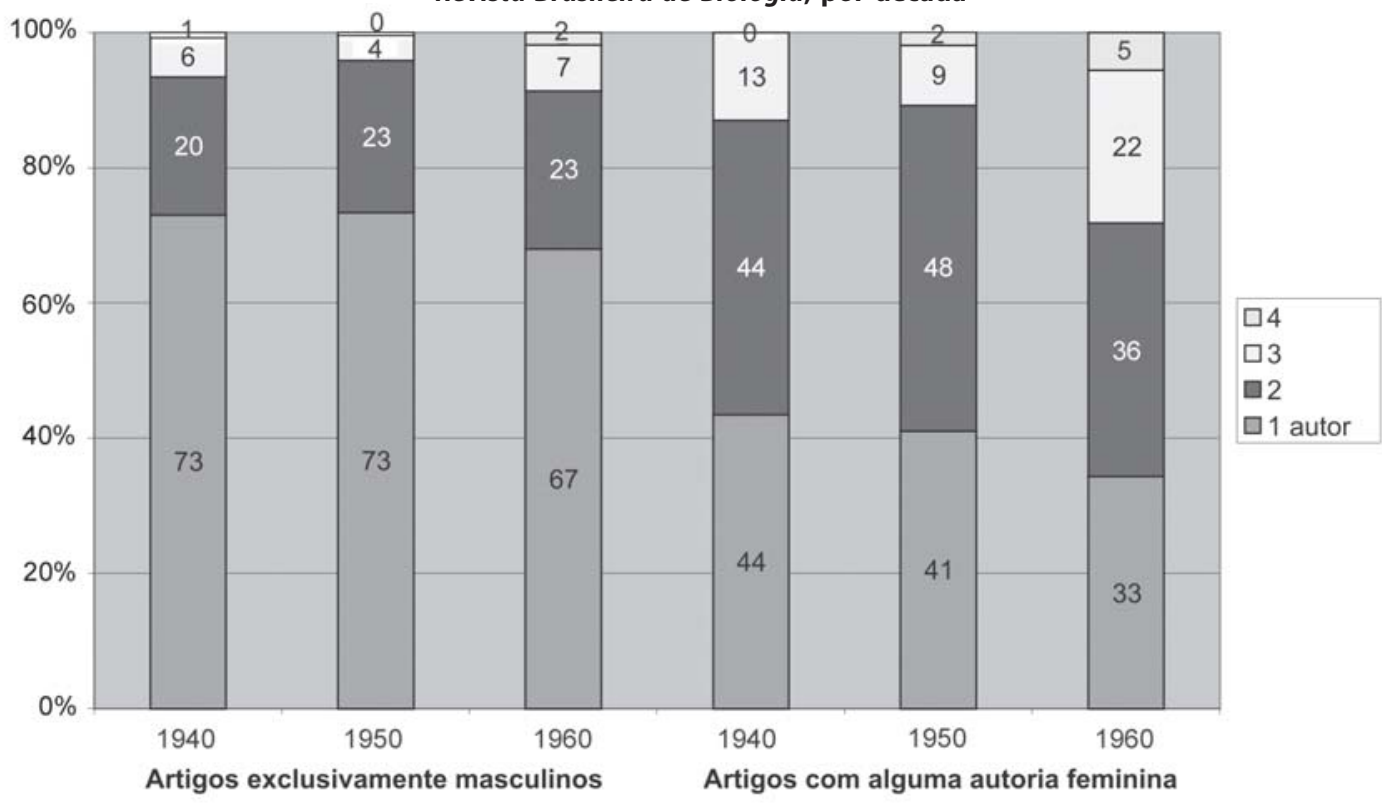

Gráfico 4

Distribuição do número de autores por artigo nos Anais da Academia Brasileira de Ciências. bor década

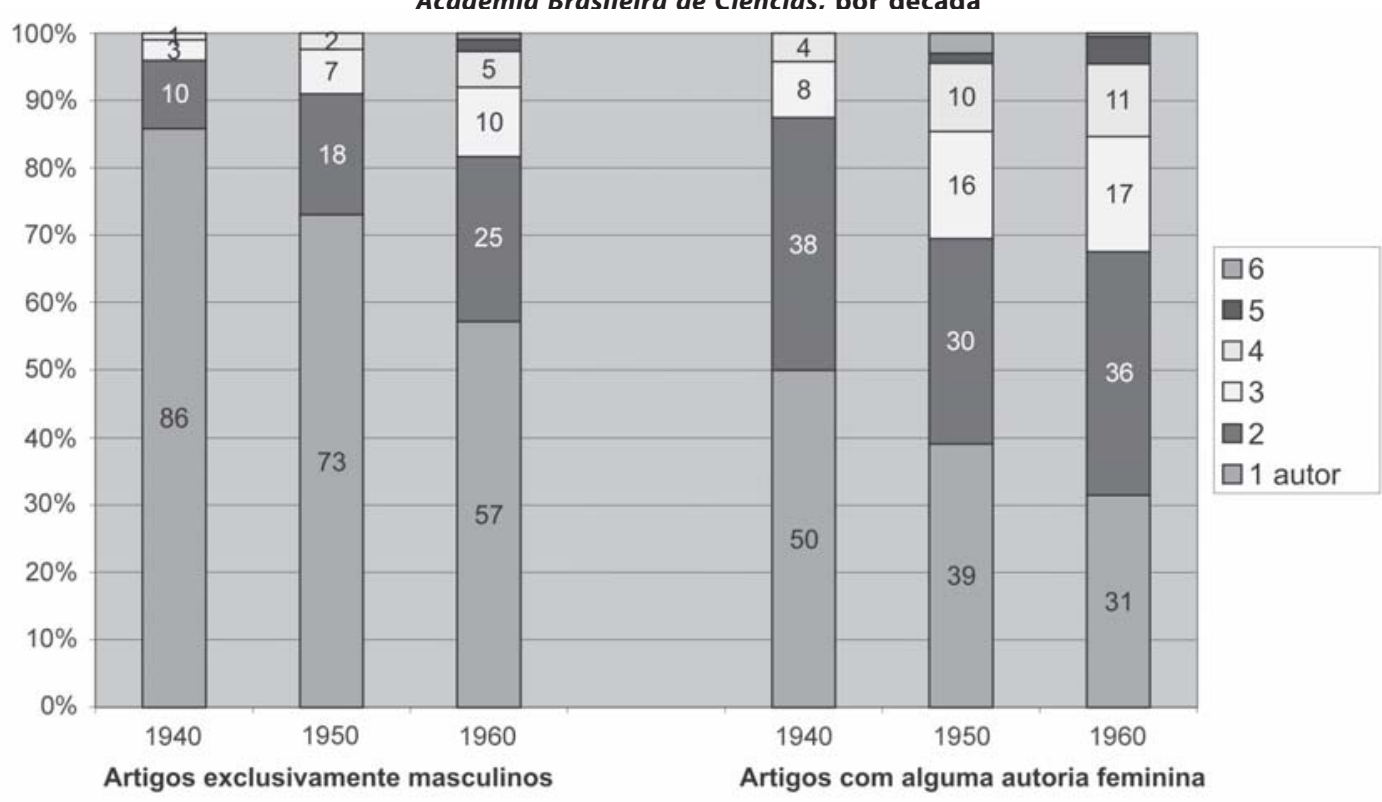

uma possibilidade de carreira, tendo em vista, entre outros aspectos, o caráter vitalício da cátedra. ${ }^{22}$ A longa permanência dessa instituição não favoreceu a adoção de uma organização ao estilo big science, como ocorreu no plano internacional após a Segunda Guerra Mundial. Em geral, a atividade científica continuaria a se organizar em uma escala 
restrita, mais aos moldes da little science, limitada à existência de um número reduzido de grupos de pesquisa, com baixo grau de colaboração e situados em um leque circunscrito de campos disciplinares, sem dispor de recursos assegurados a médio e longo prazos (Schwartzman, 1976). Não obstante, uma outra tendência, paralela, começou a se esboçar progressivamente a partir de meados dos anos 50, introduzindo mudanças, sobretudo em departamentos e institutos de algumas universidades, nos quais a carreira científica se estabeleceria com base em títulos e na produção científica, bem como na organização de equipes de pesquisa, sustentadas com auxílios estatais mais sistemáticos.

A afirmação dessas equipes como forma de organização do trabalho científico é confirmada pelos dados relativos às publicações dos Anais da Academia Brasileira de Ciências, que indicam expressivo grau de colaboração de ambos os conjuntos de artigos, enquanto na Revista Brasileira de Biologia essa nova dinâmica se refere aos artigos com alguma autoria feminina.

Em nossa opinião, a natureza da produção científica nessas revistas permite afirmar que a presença feminina constitui um fator de mudança: reflete o processo de reorganização da prática científica e, simultaneamente, atua em sua transformação. Essa dimensão se verifica também nos Gráficos 5 e 6, que analisam a posição da autoria feminina nos artigos publicados em colaboração na Revista Brasileira de Biologia e nos Anais da Academia Brasileira de Ciências, nos quais se percebe que as mulheres tendem a não ser primeiras autoras, situando-se predominantemente no lugar de segundo autor. Se tal disposição, por um lado, provavelmente decorre da ação das hierarquias científicas em que elas supostamente figurariam de maneira subordinada, por outro lado sugere a intervenção do fator geracional, dado pela recente incorporação de jovens aos laboratórios de pesquisa na posição de auxiliares e assistentes. Contudo, quando observamos uma revista com as características abertas à contribuição de vários campos disciplinares, como os Anais da Academia Brasileira de Ciências (Gráfico 6), verifica-se uma proporção expressiva de primeiras autoras em artigos com dois e três colaboradores, sugerindo liderança e autonomia intelectual.

A Tabela 1 também traz informações relevantes. Mostra que, em todas as revistas analisadas, ocorreu um movimento decrescente, em termos relativos, na publicação de artigos individuais por parte de autoras mulheres, apesar de o número absoluto desse tipo de publicação ter aumentado.

Embora não tenha sido possível identificar a natureza da co-autoria feminina - ela pode ter envolvido maridos, orientadores e colegas de trabalho -, percebe-se que a colaboração constituiu um traço marcante do padrão de publicação das mulheres naquele período, sugerindo um grau de inclusão efetivo às instituições científicas brasileiras. Nas Tabelas 2, 3, 4 e 5 procuramos capturar esse vínculo ao focalizar a instituição de origem do primeiro autor, ressaltando tanto a amplitude da inserção feminina em um leque diversificado de instituições, quanto a relevância das faculdades de filosofia. Elas não foram apenas um espaço institucional privilegiado de formação escolar, mas também o ambiente que mais lhes abriu oportunidades profissionais. Observa-se ainda uma correlação entre os dois periódicos que concentraram a maior parte da produção científica feminina - Anais da Academia Brasileira de Ciência e Revista Brasileira de Biologia - e essa extração 
Gráfico 5

Distribuição dos lugares em que primeiro aparece a autora mulher, segundo o número de autores por artigo na Revista Brasileira de Biologia

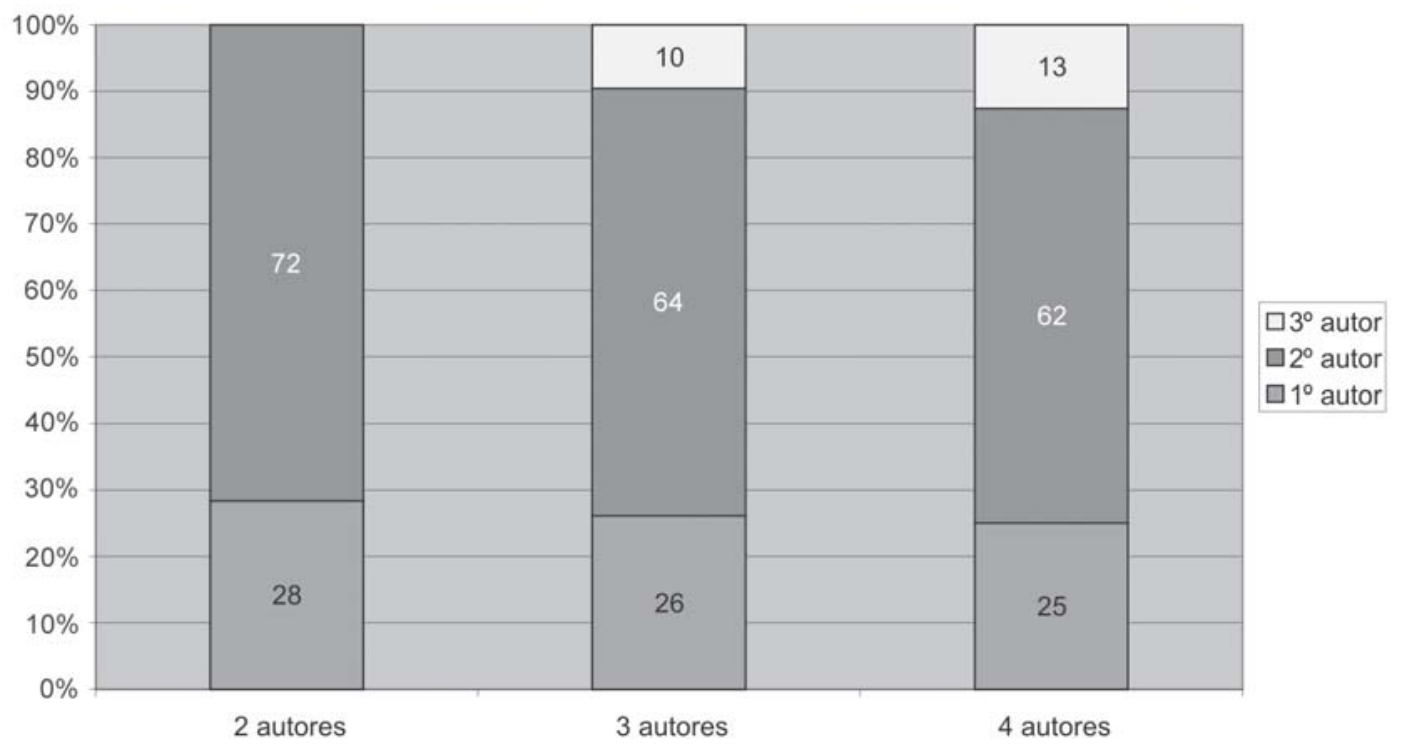

Gráfico 6

Distribuição dos lugares em que primeiro aparece a autora mulher, segundo o número de autores dos artigos nos Anais da Academia Brasileira de Ciências

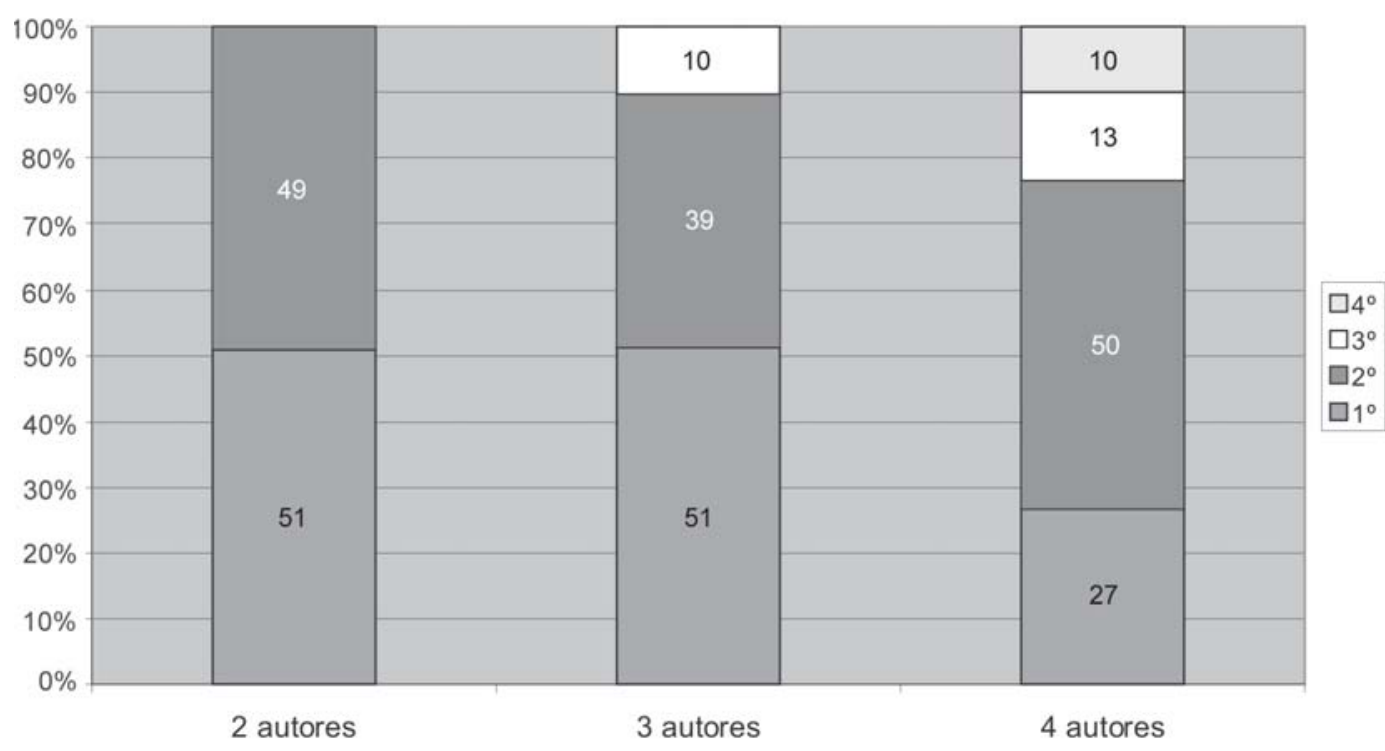


Tabela 1 - Distribuição dos artigos individuais escritos por mulheres em cada década

\begin{tabular}{|c|c|c|c|}
\hline & 1939-1949 & $1950-1960$ & 1961-1970 \\
\hline \multicolumn{4}{|l|}{ Anais da Academia Brasileira de Ciências } \\
\hline $\begin{array}{l}\text { Número absoluto } \\
\text { Percentual em relação aos escritos em colaboração }\end{array}$ & $\begin{array}{l}11 \\
45 \%\end{array}$ & $\begin{array}{l}27 \\
39 \%\end{array}$ & $\begin{array}{l}70 \\
31 \%\end{array}$ \\
\hline \multicolumn{4}{|l|}{ Revista Brasileira de Biologia } \\
\hline $\begin{array}{l}\text { Número absoluto } \\
\text { Percentual em relação aos escritos em colaboração }\end{array}$ & $\begin{array}{l}27 \\
43 \%\end{array}$ & $\begin{array}{l}23 \\
41 \%\end{array}$ & $\begin{array}{l}44 \\
33 \%\end{array}$ \\
\hline \multicolumn{4}{|l|}{ Memórias do Instituto Oswaldo Cruz } \\
\hline $\begin{array}{l}\text { Número absoluto } \\
\text { Percentual em relação aos escritos em colaboração }\end{array}$ & $\begin{array}{l}13 \\
54 \%\end{array}$ & $\begin{array}{l}22 \\
47 \%\end{array}$ & $\begin{array}{l}14 \\
31 \%\end{array}$ \\
\hline \multicolumn{4}{|l|}{ Revista Brasileira de Malariologia e Doenças Tropicais } \\
\hline $\begin{array}{l}\text { Número absoluto } \\
\text { Percentual em relação aos escritos em colaboração }\end{array}$ & - & $\begin{array}{l}8 \\
17 \%\end{array}$ & $\begin{array}{l}12 \\
26 \%\end{array}$ \\
\hline
\end{tabular}

Tabela 2 - Distribuição relativa da instituição à qual pertencia o primeiro autor dos artigos publicados nos Anais da Academia Brasileira de Ciências

\begin{tabular}{|c|c|c|c|c|c|}
\hline \multicolumn{3}{|c|}{ Artigos exclusivamente masculinos (1.199) } & \multicolumn{3}{|c|}{ Artigos com alguma autoria feminina (315) } \\
\hline 1 & Instituição não informada & 12,9 & 1 & USP/FFCL & 21,3 \\
\hline 2 & Instituto Oswaldo Cruz & 9,4 & 2 & Departamento Nacional de & \\
\hline 3 & USP/FFCL & 8,4 & 3 & USP & 7,0 \\
\hline 4 & UB /Instituto de Biofísica & 5,3 & 4 & UB/ Instituto de Biofísica & 6,7 \\
\hline \multirow[t]{2}{*}{5} & \multicolumn{2}{|l|}{ Departamento Nacional de } & 5 & Instituto Oswaldo Cruz & 6,3 \\
\hline & Produção Mineral & 4,8 & 6 & Instituto Nacional de Tecnologia & 5,4 \\
\hline 6 & Conselho Nacional de Pesquisa & 3,6 & 7 & Universidade Rural & 2,9 \\
\hline 7 & Centro Brasileiro de Pesquisas Físicas & 3,1 & 8 & Museu Nacional & 2,5 \\
\hline \multirow{2}{*}{$\begin{array}{l}8 \\
9\end{array}$} & \multirow{2}{*}{$\begin{array}{l}\text { UB/ FNFi } \\
\text { Instituto Tecnológico da Aeronáutica }\end{array}$} & \multirow{2}{*}{$\begin{array}{l}2,0 \\
1,8\end{array}$} & 9 & Outros & 40,6 \\
\hline & & & \multicolumn{2}{|r|}{ Total: } & 100 \\
\hline 11 & UPE/ Escola de Geologia e Engenharia & 1,4 & & & \\
\hline \multirow[t]{2}{*}{12} & Outros & 45,9 & & & \\
\hline & Total: & 100 & & & \\
\hline
\end{tabular}

Tabela 3 - Distribuição relativa da instituição à qual pertencia o primeiro autor dos artigos publicados na Revista Brasileira de Biologia

\begin{tabular}{|c|c|c|c|c|c|}
\hline \multicolumn{3}{|c|}{ Artigos exclusivamente masculinos (1.518 artigos) } & \multicolumn{3}{|c|}{ Artigos com alguma autoria feminina (250) } \\
\hline 1 & Instituto Oswaldo Cruz & 26,5 & 1 & Instituto Oswaldo Cruz & 18,8 \\
\hline 2 & Museu Nacional & 9,9 & 2 & USP/FFCL & 10,8 \\
\hline 3 & Instituição não informada & 4,7 & 3 & Museu Nacional & 10,4 \\
\hline 4 & Conselho Nacional de Pesquisa (CNPq) & 4,3 & 4 & USP & 3,6 \\
\hline 5 & Instituto Biológico & 2,6 & 5 & UB/Faculdade Nacional de Medicina & 3,2 \\
\hline 6 & UMG/ Faculdade de Medicina & 2,5 & 6 & UMG & 2,8 \\
\hline 7 & USP/ Faculdade de Medicina & 2,2 & 7 & Instituto Butantan & 2,4 \\
\hline 8 & Instituto Butantan & 1,8 & 8 & UB/FNFi & 2,4 \\
\hline 9 & Jardim Botânico & 1,8 & & Outros & 45,6 \\
\hline 10 & Escola Nacional de Veterinária & 1,7 & & Total: & 100 \\
\hline 11 & $\begin{array}{l}\text { Estação Experimental de Biologia } \\
\text { e Piscultura }\end{array}$ & 1,5 & & & \\
\hline 12 & $\begin{array}{l}\text { USP/ Faculdade de Higiene e } \\
\text { Saúde Pública }\end{array}$ & 1,5 & & & \\
\hline \multirow[t]{2}{*}{13} & Outros & 38,9 & & & \\
\hline & Total: & 100 & & & \\
\hline
\end{tabular}


Luiz Otávio Ferreira et al.

institucional, com destaque para a Faculdade de Filosofia, Ciências e Letras da USP. Mas, se na Revista Brasileira de Biologia nota-se o peso de instituições mais antigas, como o Instituto Oswaldo Cruz e o Museu Nacional, tradicional e majoritariamente compostas por grupos masculinos, nos Anais da Academia Brasileira de Ciências verifica-se a presença de autores vinculados a instituições com modelos organizacionais inovadores, baseados na pesquisa básica e tecnológica, como o Instituto Nacional de Tecnologia (1933), o Departamento Nacional de Produção Mineral (1934) e o Instituto de Biofísica (1945), que surgiram concomitantemente aos primeiros ingressos de mulheres na universidade e eram, provavelmente, mais permeáveis à sua participação.

As Tabelas 4 e 5 mais uma vez reiteram o caráter endógeno, comentado anteriormente, das Memórias do Instituto Oswaldo Cruz e da Revista Brasileira de Malariologia e Doenças Tropicais, nas quais os autores, em sua maioria, provêm das instituições a que esses periódicos pertenciam.

Tabela 4 - Distribuição relativa da instituição à qual pertencia o primeiro autor dos artigos publicados nas Memórias do Instituto Oswaldo Cruz

\begin{tabular}{|c|c|c|c|c|c|}
\hline \multicolumn{3}{|c|}{ Artigos exclusivamente masculinos (853) } & \multicolumn{3}{|c|}{ Artigos com alguma autoria feminina (115) } \\
\hline 1 & Instituto Oswaldo Cruz & 90,5 & 1 & Instituto Oswaldo Cruz & 79,1 \\
\hline \multirow[t]{2}{*}{2} & Outros & 9,5 & 2 & Museu Nacional (DF) & 12,2 \\
\hline & Total: & 100 & 3 & Outros & 8,7 \\
\hline & & & & Total: & 100 \\
\hline
\end{tabular}

Tabela 5 - Distribuição relativa da instituição à qual pertencia o primeiro autor dos artigos publicados na Revista Brasileira de Malariologia e Doenças Tropicais

\begin{tabular}{|c|c|c|c|c|c|}
\hline \multicolumn{3}{|c|}{ Artigos exclusivamente masculinos (708) } & \multicolumn{3}{|c|}{ Artigos com alguma autoria feminina (93) } \\
\hline 1 & MS / DNERu & 44,6 & 1 & MS/ INERu & 34,4 \\
\hline 2 & MS / Serviço Nacional de Malária & 22,2 & 2 & MS / Serviço Nacional de Malária & 29,0 \\
\hline 3 & $\mathrm{IOC}$ & 6,1 & 3 & Outros & 36,6 \\
\hline $\begin{array}{l}4 \\
5\end{array}$ & $\begin{array}{l}\text { Instituição não informada } \\
\text { USP (Faculdade de Medicina) }\end{array}$ & $\begin{array}{l}3,2 \\
2,1\end{array}$ & & Total: & 100 \\
\hline \multirow[t]{2}{*}{6} & Outros & 19,8 & & & \\
\hline & Total: & 100 & & & \\
\hline
\end{tabular}

\section{Considerações finais}

O ingresso de mulheres na carreira científica como resultado do processo de treinamento acadêmico adquirido nas faculdades de filosofia é um fenômeno ainda pouco abordado pela historiografia brasileira das ciências. Perde-se de vista, assim, a possibilidade de explorar a categoria gênero como uma variável pertinente para a análise do desenvolvimento científico e tecnológico no país.

A inserção institucionalizada de mulheres em laboratórios e grupos de pesquisa alterou a configuração eminentemente masculina do campo científico. Elas atuaram decisivamente sobre o processo de institucionalização em curso no pós-Segunda Guerra Mundial, caracterizado como um momento importante de transição de um padrão de atividade restritivo para um padrão profissional moderno, baseado em oportunidades mais amplas de acesso e na estruturação de uma carreira. 
Em que medida as relações de gênero prevalentes na sociedade brasileira se configuraram no interior do campo científico, mantendo interdependência com esse processo? Esta permanece uma questão em aberto, a requerer amplas investigações históricas. Como procuramos mostrar, a produção científica analisada neste trabalho não apenas rastreou a presença feminina nas instituições científicas, mas também mostrou, sob diversos ângulos, um padrão de publicação diferenciado entre homens e mulheres, que a nosso ver constitui um indício das implicações de gênero na estruturação das hierarquias científicas, a partir da qual se distribuem diversamente poder e status acadêmico.

É provável que o relevante crescimento da presença feminina nas faculdades de filosofia tenha incitado as principais lideranças científicas a propor a extinção dessas instituições como um dos objetivos da reforma do ensino superior. Tal reação pode ser interpretada como o encerramento da antiga querela que opunha os cientistas aos adeptos das faculdades voltadas à formação profissional e à produção de conhecimento aplicado. Este último modelo foi o que favoreceu a escolarização superior feminina e a sua profissionalização para o magistério e outras atividades pedagógicas, por conseguinte o seu ingresso no mundo das ciências.

\section{NOTAS}

${ }^{1}$ Devem ser mencionados os esforços que, na última década, vêm sendo empreendidos para introduzir as análises de gênero em estudos sobre as atividades de pesquisa cientifica e tecnológica e de ensino superior no Brasil. Uma referência nesse campo é a revista Cadernos Pagu, pertencente ao Núcleo de Estudos de Gênero da Unicamp.

${ }^{2} \mathrm{O}$ artigo científico constitui um dispositivo social mais do que um meio para a acumulação de informação, regulando, mais do que evitando, o conflito pelo estabelecimento da propriedade intelectual, que assegura prestígio e recompensas no mundo da ciência (Price, 1969, p.65-70).

3 O mecanismo de acumulação de vantagens e desvantagens, denominado por Robert Merton efeito Mateus (Matthew Effect), refere a desigual distribuição de recompensas na ciência: a acumulação de vantagem ocorre quando certos grupos dispõem de oportunidades para aumentar sua contribuição ao conhecimento, acelerando a taxa de reconhecimento e recompensas, ao passo que aqueles que não desfrutam de tais oportunidades diminuem cada vez mais as possibilidades de obtê-las (Merton, Jan. 5 1968).

${ }^{4}$ Como assinala Long (1992, p.167-168), a instituição de formação e o mentor são centrais para o êxito do desempenho acadêmico do estudante, bem como para as posições futuras e o emprego a ser conquistado. Por isso, essa fase é estratégica para o estudo das diferenças de produtividade, uma vez que até a obtenção do título de doutor as carreiras são mais similares do que se tornarão posteriormente. Ademais, as diferenças iniciais tendem a desencadear o mecanismo de acumulação de vantagens e desvantagens, essencial para se compreender o restante da carreira.

${ }^{5}$ Embora admita a existência de discriminação contra as mulheres na ciência, Cole assinala que, freqüentemente, ela se manifesta de modo sutil e é de difícil mensuração, uma vez que pode se confundir com outras formas de preconceito (Cole, 1987, p.87).

${ }^{6}$ A publicação representa apenas a parte pública da comunicação científica, pois certifica as informações e estabelece formalmente a prioridade da autoria, base primordial de reconhecimento e recompensas. Todavia, $90 \%$ do material publicado em revistas é disseminado previamente, por meio da circulação informal de preprints, que constituem um meio fundamental para a obtenção de formação relevante para o desenvolvimento, aperfeiçoamento e verificação de idéias antes de sua comunicação pública (Crane, 1988, p.41-42; Price, 1969, p.62-68). Alguns estudos mostram que as mulheres mais do que os homens dependem da literatura publicada. Isso indica que elas obtêm informação tardia e são privadas de comentários a respeito de seu trabalho (Fox, 1991, p.196). 
${ }^{7}$ Como salienta Fox (1991, p.198), embora o padrão de colaboração varie entre os campos científicos, o crescimento da especialização e das equipes trouxe dificuldades para a sustentação material do trabalho realizado isoladamente, diminuindo a produtividade e limitando as chances de recompensas profissionais. Além disso, observa-se que artigos em co-autoria têm mais possibilidade de aceitação do que os de autores únicos, e aqueles são mais citados do que estes.

${ }^{8}$ Alguns trabalhos mostram que a colaboração profissional com os esposos durante o século XIX representou uma porta de entrada para o ingresso das mulheres na ciência. Com maior ou menor dependência dos maridos, elas se beneficiaram do status adquirido com o casamento para ingressar em círculos científicos que lhes seriam vedados de outra maneira (Ogilvie, 1989).

${ }^{9}$ A Universidade do Brasil foi estabelecida em 1937 pelo projeto de reforma da educação estabelecida por Gustavo Capanema, ministro da Educação e Saúde.

${ }^{10} \mathrm{O}$ mesmo papel social de agentes do processo de modernização seria desempenhado, nas décadas seguintes, pelos licenciados egressos das faculdades de filosofia, genuínos herdeiros intelectuais dos 'normalistas', que foram responsáveis pela renovação do ensino secundário e normal, bem como pelo desenvolvimento de várias especialidades intelectuais (Corrêa, ago. 1988).

${ }^{11} \mathrm{Um}$ inquérito realizado por Hutchinson sobre a origem social dos alunos da USP demonstra que quase 80\% dessa população são compostas por filhos, netos e bisnetos de imigrantes, provenientes da classe média urbana em formação. Conforme os dados de nossa pesquisa, essa composição se reproduz na Faculdade Nacional de Filosofia da Universidade do Brasil.

12 Essa posição de privilégio social se correlacionava a um padrão de organização da ciência marcado pela ausência de mecanismos impessoais e institucionalizados de treinamento e formação científicos. A posição era sustentada pela fortuna pessoal e pelo poder de parentes e amigos. A atividade científica tendia, assim, a se constituir como um elemento de distinção e um hábito sofisticado de uma pequena elite, para quem a pesquisa representava mais uma vocação de cavalheiros ricos do que propriamente uma profissão. Embora o critério de mérito fosse considerado, as relações familísticas (pessoais) existentes entre as 'igrejinhas' - grupos organizados como clãs em torno de uma liderança carismática de mentores predominaram na formação dos agrupamentos científicos durante um longo período (Schwartzman, 2001; Zarur, 1994; Oliveira, 1985).

$13 \mathrm{O}$ projeto de pesquisa Educação e Profissionalização Feminina no Brasil: o caso da FFCL/USP e da FNFi/UB (1934-1969) é financiado pelo Papes IV - Convênio Fiocruz/CNPq.

${ }^{14}$ Vale lembrar que a única via institucionalizada disponível eram as escolas de medicina e engenharia, nichos exclusivamente masculinos de educação e profissionalização. As oportunidades de trabalho eram reduzidas a poucas instituições isoladas - museus, observatórios, centros de pesquisa agrícola e de saúde - concentradas no Rio de Janeiro e em São Paulo, com pequena capacidade para absorver pessoal (Schwartzman, 2001).

15 Essa dupla atividade foi constatada em entrevistas que realizamos entre 2003 e 2005, no âmbito da projeto Gênero e Ciência: Carreira e Profissionalização no Instituto Oswaldo Cruz, Museu Nacional e Instituto de Biofísica (1939-1968), financiado pelo CNPq.

${ }^{16}$ A escolha desses periódicos científicos deveu-se não só a critérios relacionados ao escopo do projeto Educação e Profissionalização Feminina no Brasil: o Caso da FFCL/USP e da FNFi/UB (1934-1969), que privilegia o estudo da presença feminina nos cursos de história natural, química, física e matemática, mas também à representatividade institucional e acadêmica de cada um deles ao longo do período estudado. Evidentemente, essa escolha implica certo viés que, no caso, se manifesta na predominância da produção científica relacionada ao campo do conhecimento biológico e biomédico. Todavia tal limitação não é de todo prejudicial, sobretudo quando sabemos que essa área do conhecimento reunia a mais importante parcela da comunidade científica brasileira em meados do século XX.

17 Livros de assentamento, livros IV a IX, fundo Instituto Oswaldo Cruz (Departamento de Arquivo e Documentação, Casa de Oswaldo Cruz/Fiocruz).

${ }^{18}$ Esse resultado pode apresentar alguma distorção em função das dinâmicas editoriais, a exemplo da publicação de suplementos cuja característica é a de reunir grande quantidade de artigos, como ocorreu com os Anais da Academia Brasileira de Ciências, em 1965. Outro fator, alheio à pesquisa, diz respeito à lacuna de informações decorrente da impossibilidade de localizar, nas bibliotecas consultadas, as seguintes edições: Revista Brasileira de Biologia, v.4, de 1956 e 1961; Revista Brasileira de Malariologia e Doenças Tropicais, v.2, de 1950, 1952 e 1954, e v.3 e 4, de 1966; e Anais da Academia Brasileira de Ciências, v.2, de 1946. 
${ }^{19}$ A melhor performance dessa revista ocorre na década de 1950, provavelmente devido à visibilidade que alcançou com a política de combate às doenças tropicais conduzida pelo Departamento Nacional de Endemias Rurais, pertencente ao Ministério da Saúde, ao qual se vinculava o Serviço Nacional de Malária, e que fora criado pelo governo Juscelino Kubitschek.

${ }^{20}$ A Sociedade Brasileira de Medicina Tropical (SBMT) foi fundada em 1962 com o objetivo de reunir profissionais de saúde e pesquisadores interessados no estudo das doenças tropicais, promovendo congressos anuais e reuniões médico-científicas dedicados ao debate de diferentes aspectos dos agravos à saúde em regiões tropicais, em especial Brasil e América Latina.

${ }^{21}$ Há uma diferenciação na distribuição total dos artigos publicados por mulheres em cada revista: 41\% nos Anais da Academia Brasileira de Ciências; 32\% na Revista Brasileira de Biologia; 15\% nas Memórias do Instituto Oswaldo Cruz e 12\% na Revista Brasileira de Malariologia e Doenças Tropicais.

22 Registre-se que, nas instituições científicas brasileiras, a rigidez do modelo de cátedra, particularmente nas faculdades profissionais, levou à criação de posições acadêmicas alternativas tais como livre-docente, preparador e assistente, e estas possibilitaram outras formas de inserção nesses ambientes.

\section{REFERÊNCIAS BIBLIOGRÁFICAS}

ANDRADE, Ana Maria Ribeiro.

Físicos, mésons e política: a dinâmica da ciência na sociedade. São Paulo: Hucitec; Rio de Janeiro: Museu de Astronomia e Ciências Afins. 1999.

AZEVEDO, Fernando.

Discurso do professor Fernando Azevedo, por ocasião de sua investidura na direção da Faculdade de Filosofia, Ciências, Letras e Educação da Universidade de São Paulo. (mimeo.). 1941.

AZEVEDO, Nara et al.

Gênero e ciência: a carreira científica de Aída Hassón-Voloch. Cadernos Pagu, Campinas, v.23, p.355-387. dez. 2004.

AZEVEDO, Nara; FERREIRA, Luiz Otávio. Modernização, políticas públicas e sistema de gênero no Brasil: educação e profissionalização feminina entre as décadas de 1920-1940. Cadernos Pagu, Campinas, n.27, p.217-254. jul.-dez. 2006.

BARROS, Roque Spencer Maciel de. A Ilustração brasileira e a idéia de Universidade. São Paulo: Ed.Convívio; Edusp. 1986.

BELTRÃO, Kaizô Iwakami; ALVES, José Eustáquio Diniz.

A reversão do hiato de gênero na educação brasileira no século XX. Trabalho apresentado no Encontro Nacional de Estudos Populacionais, set. 2004, Caxambu (MG). 2004.

BIELBY, William.

Sex differences in careers: is science a special case? In: Zuckerman, Harriet; Cole, Jonathan; Bruer, John (Ed.). The outer circle: women in the scientific community. New York: W.W. Norton \& Company. p.171-187. 1991.
BOTELHO, Antônio José.

The professionalization of brazilian scientists: the Brazilian Society for the Progress of Science (SPBC) and the State (1948-1960). Social Studies of Science, London, v.20, p.473-502. 1990.

BRIQUET DE LEMOS, Antonio Agenor. Análise crítica de uma revista institucional: as Memórias do Instituto Oswaldo Cruz. Cadernos de Saúde Pública, Rio de Janeiro, v.9, n.2, p.161-169. abr.-jun. 1993.

CASTRO SANTOS, Luiz Antônio; FARIA, Lina Rodrigues de.

O ensino da saúde pública no Brasil: os primeiros tempos no Rio de Janeiro. Trabalho, Educação e Saúde, Rio de Janeiro, v.4, n.2, p.291-324. set. 2006.

\section{CELESTE FILHO, Macioniro.}

A reforma universitária e a criação das faculdades de educação. Revista Brasileira de História da Educação, Brasília, n.7, p.161-188. jan.-jun. 2004.

COLE, Jonathan.

Fair science: women in the scientific community. New York: Columbia University Press. 1987.

COLE, Jonathan; ZUCKERMAN, Harriet. Marriage, motherwood and research performance in science. In: Zuckerman, Harriet; Cole, Jonathan; Bruer, John (Ed.). The outer circle: women in the scientific community. New York: W.W. Norton \& Company. p.157-170. 1991.

CORRÊA, Mariza.

A revolução dos normalistas. Cadernos de Pesquisa, São Paulo, n.66, p.13-24. ago. 1988. 
CRANE, Diana.

Invisible colleges: difusion of knowledge in scientific communities. Chicago: The University of Chicago Press. 1988.

CUNHA, Luiz Antonio. A universidade temporã: o ensino superior da Colônia à era Vargas. Rio de Janeiro: Civilização Brasileira; Ed. UFC. 1980.

CUNHA, Neiva Vieira da.

Viagem, experiência e memória: narrativas de profissionais da saúde pública dos anos 30 . Bauru (SP): Edusc; Anpocs. 2005.

DIAS, André Luís Mattedi.

As fundadoras do Instituto de Matemática e Física da Universidade da Bahia. História, Ciências, Saúde - Manguinhos, Rio de Janeiro, v.7, n.3, p.653-674. nov. 2000- fev. 2001.

EPSTEIN, Cynthia.

Constraints on excellence: structural and cultural barriers to the recognition and demonstration of achievement. In: Zuckerman, Harriet; Cole, Jonathan; Bruer, John (Ed.). The outer circle: women in the scientific community. New York: W.W. Norton \& Company. p.239-258. 1991.

FARIA, Lina Rodrigues de.

Saúde e política: a Fundação Rockefeller e seus parceiros em São Paulo. Rio de Janeiro: Ed. Fiocruz. 2007.

FARIA, Lina Rodrigues de.

Educadoras sanitárias e enfermeiras de saúde pública: identidades profissionais em construção. Cadernos Pagu, Campinas, n.27, p.173-212. jul.-dez. 2006.

FERNANDES, Ana Maria.

A construção da ciência no Brasil e a SBPC. Brasília: Ed. UnB. 2000.

FERNANDES, Florestan.

FFCL-USP: lições pedagógicas de uma crise de crescimento. In: Fernandes, Florestan. Educação e sociedade no Brasil. São Paulo: Dominus; Edusp. p.217-237. 1966.

FOX, Mary Frank.

Gender, family characteristics, and publication productivity among scientists. Social Studies of Science, London, v.35, n.1, p.131-150. 2005.

FOX, Mary Frank.

Women and scientific careers. In: Jasanoff, Sheyla et al. Handbook of science and technology studies. London: Sage Publications. p.205-223. 1995.

FOX, Mary Frank.

Gender, environmental milieu, and productivity in science. In: Zuckerman, Harriet; Cole,
Jonathan; Bruer, John (Ed.). The outer circle: women in the scientific community. New York: W.W. Norton \& Company. p.188-204. 1991.

FOX, Mary Frank; FAVER, Catherine.

Men, women and publication productivity: patterns among social work academics. The Sociological Quarterly, Greenwich, v.26, n.4, p.537-549. 1985.

HAMILTON, Wanda.

Massacre de Manguinhos: crônica de uma morte anunciada. Cadernos da Casa de Oswaldo Cruz, Rio de Janeiro, v.1, n.1, p.7-18. 1989.

HUTCHINSON, Bertram.

Aspectos da educação universitária e status social em São Paulo. Educação e Ciências Sociais, Rio de Janeiro, v.2, n.4, p.39-76. mar. 1957.

HUTCHINSON, Bertram.

Origem sócio-econômica dos estudantes universitários de São Paulo. Educação e Ciências Sociais, Rio de Janeiro, v.1, n.3, p.91-107. dez. 1956.

LIMONGI, Fernando.

Mentores e clientela da Universidade de São Paulo. In: Miceli, Sérgio (Org.). História das ciências sociais no Brasil. v.1. São Paulo: Vértice. 1989.

LONG, J. Scott.

Measures of sex differences in scientific productivity. Social Forces, Chapel Hill, v.71, n.1, p.159-178. 1992.

LONG, J. Scott.

The origins of sex differences in science. Social Forces, Chapel Hill, v.68, n.4, p.1297-1315. 1990.

MELO, Hildete Pereira de.

A produção científica brasileira no feminino. Cadernos Pagu, Campinas, n.27, p.301-331. jul.-dez. 2006.

MENDONÇA, Ana Waleska.

A universidade no Brasil. Revista Brasileira de Educação, Brasília, n.14, p.131-150. maio-ago. 2000.

MERTON, Robert K.

The Matthew effect in science. Science, Washington, v.159, n.3810, p.56-63. Jan. 51968.

OGILVIE, Marilyn.

Marital collaboration: an approach to science. In: Abir-Am, Pnina; Outram, Dorinda (Ed.). Uneasy careers and intimate lives: women in science (1789-1979). London: Rutgers University Press. p.104-124. 1989. 
OLIVEIRA, João Batista Araújo e.

Ilhas de competência: carreiras científicas no Brasil. São Paulo; CNPq. 1985.

PAIM, Antônio.

Por uma universidade no Rio de Janeiro. In: Schwartzman, Simon (Org.). Universidades e instituições científicas no Rio de Janeiro. Brasília: CNPq. 1982.

PAULINY, Erno.

Esboço histórico da Academia Brasileira de Ciências. Brasília: CNPq. 1981.

PEREIRA, Júlio Emílio Diniz.

Relações de poder no interior do campo universitário e as licenciaturas. Cadernos de Pesquisa, São Paulo, n.11, p.183-201. dez. 2000.

PINOTTI, Mário.

Revista Brasileira de Malariologia, Rio de Janeiro, v.1, n.1. jan. 1949.

PRICE, Derek de Solla.

Little science, big science. New York: Columbia University Press. 1969.

RAGO, Elisabeth Juliska.

Medicina e feminismo no início do século XX: Francisca Praguer Fróes (Bahia: 1872-1931).

Revista do Instituto Histórico e Geográfico

Brasileiro, Rio de Janeiro, v.163, n.415, p.53-66. abr.-jun. 2002.

RAGO, Elisabeth Juliska.

A ruptura do mundo masculino da medicina: médicas brasileiras no século XIX. Cadernos Pagu, Campinas, v.15, p.199-225. 2000.

RIBEIRO, Maria Alice.

História, ciência e tecnologia: 70 anos do Instituto Biológico de São Paulo na defesa da agricultura. São Paulo: Instituto Biológico de São Paulo. 1998

ROSSITER, Margareth.

The Matthew Matilda efect in science. Social Studies of Science, London, v.23, n.2, p.325-341. 1993.

ROSSITER, Margareth.

Women scientists in America: struggles and strategies to 1940. Baltimore: The Johns Hopkins University Press. 1984.

SCHWARTZMAN, Simon.

Um espaço para a ciência: a formação da comunidade científica no Brasil. Brasília: CGEE/ MCT. 2001.
SCHWARTZMAN, Simon.

Formação da comunidade científica no Brasil. São Paulo: Cia. Ed. Nacional; Rio de Janeiro: Finep. 1979.

SCHWARTZMAN, Simon.

Ciência e história da ciência. Rio de Janeiro:

Grupo de Estudos sobre o Desenvolvimento da Ciência / Finep. Documento de Trabalho n.2

(mimeo.). Disponível em: http://

www.schwartzman.org.br/simon/

cciencia.htm\#_1_2. 1976.

SEVCENKO, Nicolau.

Introdução. O prelúdio republicano, astúcias da ordem e ilusões do progresso. In: Sevcenko, Nicolau (Org.). História da vida privada no Brasil. República: da Belle Époque à Era do Rádio. São Paulo: Companhia das Letras. p.7-48. 1998.

\section{SEVCENKO, Nicolau.}

Orfeu extático na metrópole. São Paulo: sociedade e cultura nos frementes anos 20. São Paulo: Companhia das Letras. 1992.

TRIGO, Maria Helena Bueno.

A mulher universitária: códigos de sociabilidade e relações de gênero. In: Bruschini, Cristina; Sorj, Bila (Org.). Novos olhares: mulheres e relações de gênero no Brasil. São Paulo: Marco Zero. 1994.

ZARUR, George de Cerqueira Leite. $A$ arena centífica. Campinas: Editores Associados; Flacso. 1994.

ZUCKERMAN, Harriet.

The careers of men and women scientists: a review of current research. In: Zuckerman, Harriet; Cole, Jonathan; Bruer, John (Ed.). The outer circle: women in the scientific community. New York: W.W. Norton \& Company. p.27-56. 1991.

ZUCKERMAN, Harriet; COLE, Jonathan; BRUER, John.

Introduction. In: Zuckerman, Harriet; Cole, Jonathan; Bruer, John (Ed.). The outer circle: women in the scientific community. New York: W.W. Norton \& Company. p.11-24. 1991. 